\title{
The Effect of Processing Route on the Thermoelectric Performance of Nanostructured $\mathrm{CuPb}_{18} \mathrm{SbTe}_{20}$
}

Bhuvanesh Srinivasan*a,b ${ }^{*}$ Bruno Fontaine ${ }^{a}$, Francesco Gucci ${ }^{b}$, Vincent Dorcet ${ }^{a}$, Theo Graves Saunders ${ }^{b}$, Min $\mathrm{Yu}^{\mathrm{b}}$, François Cheviréa ${ }^{\mathrm{a}}$, Catherine Boussard-Pledel ${ }^{\mathrm{a}}$, Jean-François Halet ${ }^{\mathrm{a}}$, Régis Gautier*a, Michael J. Reece $^{\mathrm{b}}$ and Bruno Bureau ${ }^{\mathrm{a}}$

a University of Rennes, Ecole Nationale Supérieure de Chimie de Rennes, CNRS, ISCR - UMR 6226, F-35000 Rennes, France.

${ }^{b}$ Nanoforce Technology Ltd., School of Engineering and Materials Science, Queen Mary University of London, London E1 4NS, United Kingdom.

* Correspondence: bhuvanesh.srinivasan@univ-rennes1.fr (BS); \$ Supporting Information (SI) available

\section{Abstract}

The quaternary $\mathrm{AgPb}_{18} \mathrm{SbTe}_{20}$ compound (abbreviated as LAST) is a prominent thermoelectric material with good performance. Endotaxially embedded nanoscale Ag-rich precipitates contribute significantly to decreased lattice thermal conductivity $\left(\kappa_{\text {latt }}\right.$ ) in LAST alloys. In this work, Ag in LAST alloys was completely replaced by the more economically available $\mathrm{Cu}$. Herein, we conscientiously investigated the different routes of synthesizing $\mathrm{CuPb}_{18} \mathrm{SbTe}_{20}$ after vacuum-sealed tube melt processing, including: (i) slow cooling of the melt; (ii) quenching and annealing; (iii) consolidation by spark plasma sintering (SPS); and also by the state-of-the-art (iv) Flash-SPS. Irrespective of the method of synthesis, the electrical $(\sigma)$ and thermal $\left(\kappa_{\text {tot }}\right)$ conductivities of $\mathrm{CuPb}_{18} \mathrm{SbTe}_{20}$ samples were akin to that of LAST alloys. Both the flash-SPSed and the slow cooled $\mathrm{CuPb}_{18} \mathrm{SbTe}_{20}$ samples with nanoscale dislocations and $\mathrm{Cu}$-rich nanoprecipitates exhibited an ultra-low $\mathrm{K}_{\mathrm{att}} \sim 0.58 \mathrm{~W} / \mathrm{mK}$ at $723 \mathrm{~K}$, comparable with that its $\mathrm{Ag}$ counterpart, regardless of differences in their size of the precipitates, type of precipitate-matrix interfaces and other nanoscopic architectures. The sample processed by flash sintering manifested higher figure of merit ( $z T \sim 0.9$ at $723 \mathrm{~K}$ ), due to better optimization and trade-off between the transport properties by decreasing the carrier concentration and $\kappa_{\text {latt }}$ without degrading the carrier mobility. In spite of their comparable $\sigma$ and $\kappa_{\text {tot }}$, the $z T$ of the Cu samples were low compared to the $\mathrm{Ag}$ samples due to their contrasting thermopower values. First-principles calculations attribute this variation in Seebeck to the dwindling of the energy gap (from $0.1 \mathrm{eV}$ to $0.02 \mathrm{eV}$ ) between the valence and conduction bands in $\mathrm{MPb}_{18} \mathrm{SbTe}_{20}(\mathrm{M}=\mathrm{Cu}$ or $\mathrm{Ag})$, when $\mathrm{Cu}$ replaces $\mathrm{Ag}$. 


\section{Introduction}

Environmental concerns due to climate change arising from increased $\mathrm{CO}_{2}$ emissions and exploitation of fossil fuel reserves poses a great challenge to the society on a global scale. ${ }^{1-3}$ Thermoelectric (TE) materials and devices, with their potential to convert between thermal and electrical energy, provide an alternative route for power generation and refrigeration. They are expected to play a key role in meeting the energy demands of the future..$^{4-7}$ The efficiency of a TE material to convert waste heat into fruitful electricity is quantified by a dimensionless figure of merit, $z T$

$$
z T=\frac{S^{2} \sigma T}{\kappa_{\text {tot }}}
$$

where $S, \sigma, T$ and $\kappa_{\text {tot }}$ are Seebeck coefficient (also referred as thermopower), electrical conductivity, temperature and total thermal conductivity (sum of the electronic part $\kappa_{\mathrm{e}}$ and the lattice part $\kappa_{\text {latt }}$ ), respectively.

The fact that these thermoelectric transport properties are highly interrelated complicates attempts to enhance $z T$. Advances in recent times show that it is feasible to enhance $z T$ by a number of approaches: (i) quantum confinement of electron charge carriers; ${ }^{8}$ (ii) synergistic nano-structuring; ${ }^{9-13}$ (iii) nanoinclusions, which enable acoustic phonon scatterings; ${ }^{14,15}$ (iv) electron filtering; ${ }^{16}$ (v) convergence of electronic band valleys; ${ }^{17-20}$ (vi) fostering resonant levels by impurities inside the valence band; ${ }^{21}$ (vii) alloying to create point defects; ${ }^{22-24}$ (viii) complex crystal structures like skutterudites, ${ }^{25,26}$ Zintl compounds, ${ }^{27,28}$ hetero-structured superlattice thin-films; ${ }^{29}$ (ix) semi-conducting glasses, ${ }^{30-34}$ and $(x)$ utilization of magnetism, ${ }^{35-38}$ for instance.

Spark Plasma Sintering (SPS), involving direct Joule heating of electrically conductive dies (usually graphite), has been widely used to produce nanostructured materials, especially for thermoelectrics. ${ }^{10,39,40}$ More recently, a novel sintering process called 'Flash-SPS', a derivative of the flash and SPS sintering techniques has generated a lot of interest as it has been shown to improve the thermoelectric performance of Mg-Si based materials. ${ }^{41}$ During SPS, the heating rate typically used is $\sim 100{ }^{\circ} \mathrm{C} / \mathrm{min}$, whereas the flash technique employs thermal runaway to achieve ultra-fast sintering with heating rate as high as $\sim 10,000{ }^{\circ} \mathrm{C} / \mathrm{min}$, producing dense materials in a matter of few seconds. ${ }^{42-45} \mathrm{An}$ additional advantage of the flash-SPS method is that no preheating is required when conducting samples are used. Though flash sintering has been used predominantly to process high temperature ceramics like $\mathrm{SiC}^{44,46}$ $\mathrm{ZrO}_{2},{ }^{42} \mathrm{ZrB}_{2}{ }^{47}$ it has not been tried on many thermoelectric materials. For this reasons, the flash-SPS process, infact its variant 'Hybrid Flash-SPS' was used in this work to prepare PbTe based materials. More 
details regarding this state-of-the-art 'Hybrid flash-SPS' technique are provided in the materials and methods section (synthesis part).

Lead tellurides are one of the most studied and earliest known class of TE materials. ${ }^{5}$ Several strategies, some of them mentioned earlier, have successfully been employed on the binary $\mathrm{PbTe}$ compound to maximize its performance. Most notably, Kanatzidis' group ${ }^{48}$ made a breakthrough in 2004, when a material of composition $\mathrm{AgPb}_{18} \mathrm{SbTe}_{20}$, abbreviated as LAST (Lead-Antimony-Silver-Tellurium), reportedly exhibited a high $z T \sim 2.2$ at $800 \mathrm{~K}$. Independent studies based on different synthesis routes of this LAST alloy have reported consistently high $z T$ in the range of $1.3-1.5$ at around $700 \mathrm{~K} .{ }^{49-52}$ Various explanations for the very high $z T$ of LAST alloys have been proposed: (i) the presence of coherent, endotaxially embedded nanoscopic inhomogeneity or nanodots (rich in Ag and $\mathrm{Sb}$ ) in the PbTe matrix and/or modulated nanostructures and atomic ordering; ${ }^{48,53-57}$ and (ii) to the presence of resonance states in the electronic band structure of bulk PbTe when $\mathrm{Ag}$ and $\mathrm{Sb}$ partially substitute for $\mathrm{Pb}$ and/or sizable band-gap widening caused by nanodopant induced lattice strains. ${ }^{58-60}$

Building on the work by Kanatzidis et al., ${ }^{48}$ several papers have been published on replacing one or more of the elements in LAST alloys in an attempt to improve $z T$, such as substituting $\mathrm{K}$ for Ag to make $n$-type $\mathrm{K}_{1-x} \mathrm{~Pb}_{\mathrm{m}+\delta} \mathrm{Sb}_{1+\gamma} \mathrm{Te}_{\mathrm{m}+2}(z T \sim 1.6$ at $750 \mathrm{~K}),{ }^{15} \mathrm{Na}$ for Ag to make $p$-type $\mathrm{Na}_{1-\mathrm{x}} \mathrm{Pb}_{\mathrm{m}} \mathrm{Sb}_{\mathrm{y}} \mathrm{Te}_{\mathrm{m}+2}(z T \sim 1.7$ at $650 \mathrm{~K}),{ }^{11} \mathrm{La}$ for $\mathrm{Sb}$ to make $n$-type $\mathrm{Ag}_{n} \mathrm{~Pb}_{1-x} \operatorname{La}_{x} T e(z T \sim 1.2 \text { at } 720 \mathrm{~K})^{61}$ Bi for $\mathrm{Sb}$ to make $n$-type $\operatorname{AgPb}_{\mathrm{m}} \mathrm{BiTe}_{\mathrm{m}+2}(z T \sim 0.5$ at $650 \mathrm{~K}),{ }^{62}$ and $\mathrm{Cl}$ codoped with Se for Te to make $n$-type $\mathrm{AgPb}_{\mathrm{m}} \mathrm{SbSe}_{(\mathrm{m}+2)-\mathrm{x}} \mathrm{Cl} \mathrm{l}_{x}(z T \sim 1.3$ at $873 \mathrm{~K}) .{ }^{63}$ However, one obvious substitution has not yet been investigated, replacing Ag with chemically similar coinage metal like $\mathrm{Cu}$ or $\mathrm{Au}, \mathrm{Cu}$ substitution is particularly interesting due to its much lower cost.

This paper presents a comparison between the thermoelectric properties of nanostructured LAST alloys (as reported by Kanatzidis et al. ${ }^{48}$ ) and those of its $\mathrm{Cu}$ counterpart, i.e., $\mathrm{CuPb}_{18} \mathrm{SbTe}_{20}$, examining experimental and theoretical aspects. For a more complete understanding on the effect of synthesis conditions on the thermoelectric properties of $\mathrm{CuPb}_{18} \mathrm{SbTe}_{20}$, samples were synthesized by many different routes, namely: (i) slow cooling of the melt; (ii) rapid quenching; (iii) Spark Plasma Sintering; and (iv) Hybrid flash-SPS. Additionally, first-principles calculations were carried out in order to understand the differences in the physical properties and electronic band structures of $\mathrm{AgPb}_{18} \mathrm{SbTe}_{20}$ and $\mathrm{CuPb}_{18} \mathrm{SbTe}_{20}$. DFT calculations were also extended to the gold clusters $\left(\mathrm{AuPb}_{18} \mathrm{SbTe}_{20}\right)$ to convey a comprehensive picture of the influence of group-11 transition metals on the thermoelectric behavior of $\mathrm{MPb}_{18} \mathrm{SbTe}_{20}(\mathrm{M}=\mathrm{Cu}, \mathrm{Ag}$, $\mathrm{Au})$. 


\section{Materials and Methods}

\section{Reagents}

$\mathrm{Pb}$ (Strem Chemicals, 99.999\%), Sb (Alfa Aesar, 99.999\%), Cu (Alfa Aesar, 99.999\%) and Te (JGI, 99.999\%) were used for synthesis without any further purification.

\section{Synthesis}

In this work, several different processing routes were investigated, however, the first step (synthesis) was common to all of the processing routes. Samples of $\mathrm{CuPb}_{18} \mathrm{SbTe}_{20}$ were synthesized using the vacuumsealed tube melt processing. Stoichiometric amounts of the starting elements of $\mathrm{Cu}, \mathrm{Pb}, \mathrm{Sb}$ and Te were introduced into a fused silica tube. The tube was prepared by cleaning with hydrofluoric (HF) acid and distilled water, then dried under vacuum. The ampoules were sealed under a vacuum of $10^{-6}$ Torr, then placed in a rocking furnace and slowly heated to $1223 \mathrm{~K}$ over a period of 12 hours, then held at that temperature for 15 hours. Four different batches of samples were prepared, the first two were produced directly from the molten material, followed by: (i) cooling the melt to room temperature over a period of 18 hours (samples denoted as 'SS'); (ii) rapidly quenching the tube in water, followed by annealing at 973 $\mathrm{K}$ for 8 hours (denoted as ' $M Q$ '). The other two batches used the material produced by method (i), which was crushed and milled. The powders were then (iii) consolidated by Spark Plasma sintering, SPS (FCT Systeme $\mathrm{GmbH}$ ) at $673 \mathrm{~K}$ (heating rate $\sim 80^{\circ} \mathrm{C} / \mathrm{min}$ ) for 5 mins (holding time) under an axial pressure of $85 \mathrm{MPa}$; and (iv) consolidated by 'Hybrid' Flash-SPS processing, where the powders were sintered at 800 $\mathrm{K}$ with no holding time and a heating rate of $\sim 10,000^{\circ} \mathrm{C} / \mathrm{min}$ (heated from $293-800 \mathrm{~K}$ in 3 seconds) under an axial pressure of $80 \mathrm{MPa}$. Typically during a Flash-SPS process, the green compact was sandwiched between two graphite punches without a die and inserted in between the pistons of the SPS furnace. ${ }^{41}$ But the 'Hybrid Flash-SPS' processing route is a variant of the originally developed Flash-SPS method, involving the use of a thin, low thermal inertia metal die to contain the TE powder during sintering. ${ }^{64,65}$ The schematics of the experimental set-up and the current flow paths for SPS (graphite punches and die), Flash-SPS (graphite punches and no die) and Hybrid Flash-SPS (graphite punches and a thin walled stainless steel die) configurations are depicted in Figure 1. More details are available in the Supporting Info (SI, Table S1). Highly dense disk-shaped pellets were obtained with theoretical densities of $100 \%$ for SPS and $\sim 98 \%$ for Hybrid Flash-SPS. The obtained ingots and sintered discs were cut and polished to the required shapes and dimensions for various thermoelectric measurements. 

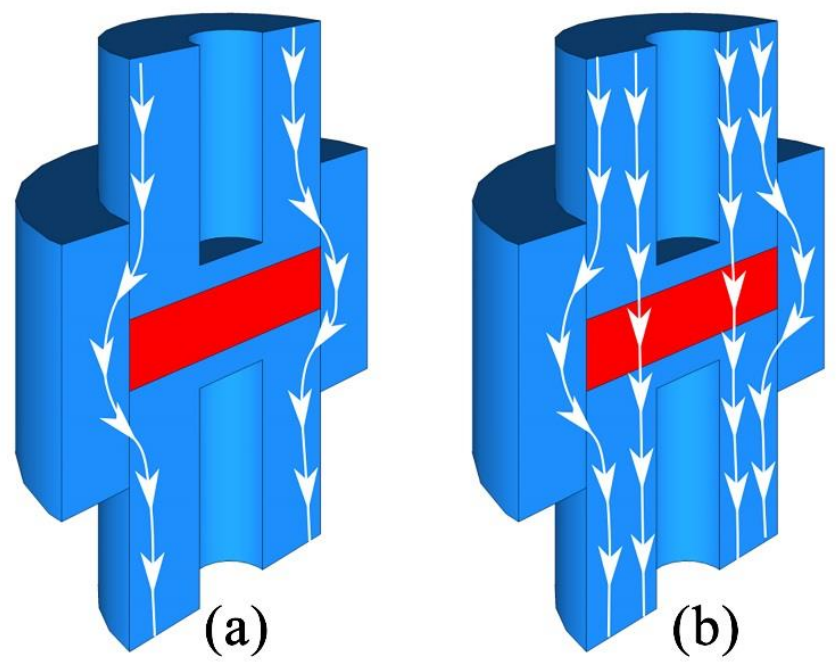

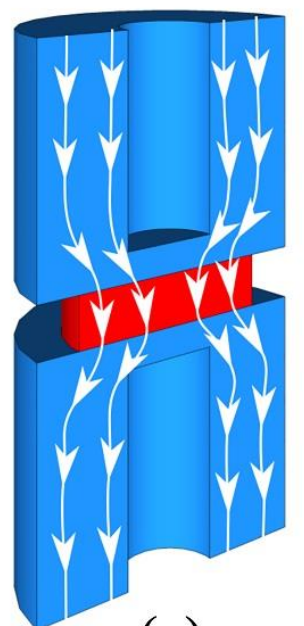

(c)

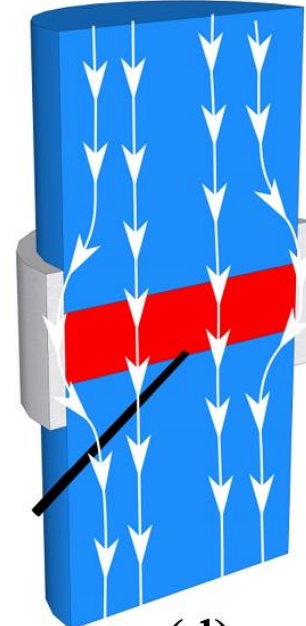

(d)

Figure 1. Flow of current in different sintering configurations - $(a, b)$ In SPS set-up (with graphite punches and die) for high and low resistive samples, (c) Flash-SPS (graphite punches and no die), and (d) Hybrid Flash-SPS (graphite punches and a thin walled stainless steel die) configurations. Additional details pertaining to each configuration are presented in SI (Table S1).

\section{Powder X-ray diffraction}

$X$-ray diffraction (XRD) patterns were recorded at room temperature in the $2 \theta$ range $15-120^{\circ}$ with a step size of $0.026^{\circ}$ and a scan time per step of 400 s using a PANalytical X'Pert Pro diffractometer (Cu $K-L_{2,3}$ radiation, $\lambda=1.5418 \AA$, PIXcel $1 \mathrm{D}$ detector). The lattice parameters were estimated from Lebail-type profile fits carried out with the Fullprof program and the Pseudo-Voigt profile function. ${ }^{66}$

\section{Hall measurements}

The Hall measurements were carried out at room temperature using a home-made four-point probe setup (van der Pauw method), where a fixed magnetic field of 0.112 T and a dc current of $15 \mathrm{~mA}$ were applied. The measurements were made on square-shaped samples of dimensions $\sim 5 \times 5 \times 2 \mathrm{~mm}^{3}$. The carrier concentration $(n)$ and charge carrier mobility $\left(\mu_{c}\right)$ were computed from carrier sheet density $\left(n_{\mathrm{s}}\right)$, sheet resistance $\left(R_{\mathrm{s}}\right)$ and Hall Voltage $\left(V_{\mathrm{H}}\right)$ using the following equations,

$$
\begin{aligned}
& n_{s}=n t=\frac{I B}{e\left|V_{\mathrm{H}}\right|} \\
& \mu_{\mathrm{c}}=1 /\left(e n_{\mathrm{s}} R_{\mathrm{s}}\right)
\end{aligned}
$$


where $e, B, l$ and $t$ are the charge of the electron, magnetic field, current and thickness of the sample, respectively. The values of carrier density obtained were quite consistent with an error of less than $2 \%$.

\section{Electrical and thermal transport}

For each sample, the electrical resistivity and Seebeck coefficient was measured simultaneously from room temperature to $723 \mathrm{~K}$ using a commercial instrument (LSR-3, Linseis Inc.), in He atmosphere. The measurements were made on rectangular samples of dimension $\sim 10 \times 2 \times 2 \mathrm{~mm}^{3}$.

The thermal diffusivity, $D$ was measured from room temperature to $723 \mathrm{~K}$ using the laser flash diffusivity method in a Netzsch LFA-457 instrument. Disk-shaped samples of $10 \mathrm{~mm}$ diameter and $-2 \mathrm{~mm}$ thickness were used for the measurements. The temperature dependent heat capacity, $C_{p}$, was derived using the Dulong-Petit relation as in equation (4),

where $R$ is the gas constant and $M$ is the molar mass.

The total thermal conductivity $\kappa_{\text {tot }}$ was calculated using equation (4),

$$
\kappa_{\text {tot }}=D C_{p} \rho
$$

where $\rho$ is the density of the sample. The density of the disks was measured using Archimedes' principle. To better understand the thermal transport properties, the contributions from electronic and lattice parts were calculated. The lattice thermal conductivity $\left(\kappa_{\text {latt }}\right)$ was estimated from $\kappa_{\text {tot }}$ by subtracting the electronic contribution ( $\kappa_{\mathrm{e}}$ ) via Wiedemann-Franz law, as in equation (6),

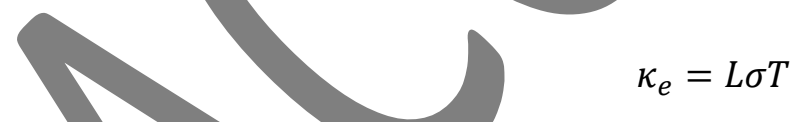

where $\kappa_{\mathrm{e}}$ is the electronic thermal conductivity and $L$ is the Lorenz number computed by the condensed version of Single Parabolic Band model with acoustic phonon scattering (SPB-APS), ${ }^{20,67}$ as in equation (7)

$$
L=1.5+\exp \left[-\frac{|S|}{116}\right]
$$

where Seebeck coefficient $(S)$ is in $\mu \mathrm{VK}^{-1}$ and Lorenz number $(L)$ is in $10^{-8}{\mathrm{~W} \Omega K^{-2}}^{\text {. }}$

The uncertainty in the results for the values of electrical and thermal transport properties was $\sim 5 \%$ and $\sim 7 \%$, respectively and for the overall $z T$ was $\sim 12 \%$. Error bars are not shown in the figures to increase readability.

\section{Microscopic analysis}


Transmission electron microscopy (TEM) investigations were carried out (JEOL 2100F) on electrontransparent samples prepared by polishing, dimpling, and ion beam milling. Scanning electron microscopy (SEM) analysis was performed using a JEOL JSM 7100F microscope on the fractured surface of the samples.

\section{Computational procedures}

Density functional theory (DFT) geometry optimizations of $\mathrm{MPb}_{18} \mathrm{SbTe}_{20}(\mathrm{M}=\mathrm{Cu}, \mathrm{Ag}, \mathrm{Au}$ ) were carried out with the CASTEP16.1 code $^{68}$ using the GGA in the parameterization of PBE functional. ${ }^{69}$ In order to simulate a stoichiometry relevant to $\mathrm{MPb}_{18} \mathrm{SbTe}_{20}$ compounds, a supercell was considered from the cubic cell of the PbTe structure. Several supercells were tested and a $1 \times 1 \times 5$ supercell was chosen, since it was the simplest supercell that correctly predicted semiconducting behavior and was the most stable one among the supercells that were considered. In this supercell, the Sb atom lies at the origin, whereas the Group-11 metal lies at the next nearest neighboring site. Previous theoretical studies demonstrated that the Ag-Sb pair stabilized when it forms the nearest neighbor in the PbTe matrix. ${ }^{60}$ Therefore, $\mathrm{M}$ and $\mathrm{Sb}$ atoms were located in the same layer normal to the [0 01$]$ direction, and separated by five $\mathrm{Pb}$ layers. Cell parameters and atomic positions were both relaxed. All ultra-soft pseudopotentials were generated using the OTF generator included in the program. The cut-off energy for plane-waves was set at $500 \mathrm{eV}$. The electronic wave function was sampled with $110 k$-points in the first Brillouin zone using the MonkhorstPack method. ${ }^{70}$ For the electronic band structures, the full-potential linearized augmented plane wave (FLAPW) approach was used, as implemented in the WIEN2K code. ${ }^{71}$ Since GGA exchange-correlation functionals are known to underestimate experimental band gaps, the modified Becke-Johnson (mBJ) functional proposed by Tran and Blaha was utilized. ${ }^{72}$ This functional yields band gaps with an accuracy similar to hybrid functional or GW methods, but are obtained at a considerably reduced computational effort. A plane wave cut-off corresponding to $R_{M T} K_{\max }=7$ was used. The radial wave functions inside the non-overlapping muffin-tin spheres were expanded up to $I_{\max }=12$. The charge density was Fourier expanded up to $G_{\text {max }}=12 \AA^{-1}$. Total energy convergence was achieved with a Brillouin zone (BZ) integration mesh of $500 k$-points.

The carrier effective mass $\left(m^{*}\right)$ was derived for each sample using a single parabolic band model ${ }^{73,74}$ and the measured room temperature Seebeck coefficient $(S)$ and carrier concentration $(n)$. The chemical potential $(\mu)$ was estimated using equation (8) with $\lambda=0$ (acoustic-phonon scattering), where $F_{j}(\mu)$ is the Fermi integrals given by equation (9). The hole effective mass can then be determined from equation (10). 


$$
\begin{gathered}
S=\frac{K_{B}}{e}\left\{\frac{(2+\lambda) F_{1+\lambda}(\mu)}{(1+\lambda) F_{\lambda}(\mu)}-\mu\right\} \\
F_{j}(\mu)=\int_{0}^{\infty} \frac{\xi^{j} d \xi}{1+e^{(\xi-\mu)}} \\
m^{*}=\frac{h^{2}}{2 k_{B} T}\left[\frac{n}{4 \pi F_{1 / 2}(\mu)}\right]^{2 / 3}
\end{gathered}
$$

Transport properties were computed using a semi-classical approach. The electronic transport coefficients for $\mathrm{MPb}_{18} \mathrm{SbTe}_{20}(\mathrm{M}=\mathrm{Cu}, \mathrm{Ag}, \mathrm{Au})$ were calculated using the Boltzmann Transport Equation (BTE) and the constant scattering time and the rigid band structure approximation, ${ }^{55,76}$ as implemented in the BoltzTrap1.2.5 code. $^{77} 5000 k$-points were used in the BZ to compute the band derivatives for the transport calculations.

\section{Results and Discussion}

Powder XRD patterns of all the samples of $\mathrm{CuPb}_{18} \mathrm{SbTe}_{20}$ are shown in Figure 2. Sharp peaks indicate the polycrystalline nature of the phases. The majority of the patterns were consistent with the cubic $\mathrm{NaCl}$ type $\mathrm{PbTe}$ structure $(\mathrm{Fm}-3 \mathrm{~m})$. In the case of the slow cooled sample (SS), a few minor peaks from secondary phases of $\mathrm{Sb}_{2} \mathrm{Te}_{3}$ (trigonal, $R-3 \mathrm{~m}$ ) and $\mathrm{Cu}_{2} \mathrm{Te}$ (hexagonal, $P 3 m 1$ ) were present. The presence of these weak secondary reflections can be attributed to the low solubility of $\mathrm{Sb}$ and $\mathrm{Cu}$ in PbTe. ${ }^{23,78,79}$ The absence of any secondary phase in the SPS and the flash samples shows that the equilibrium solubility can be exceeded by rapid cooling.

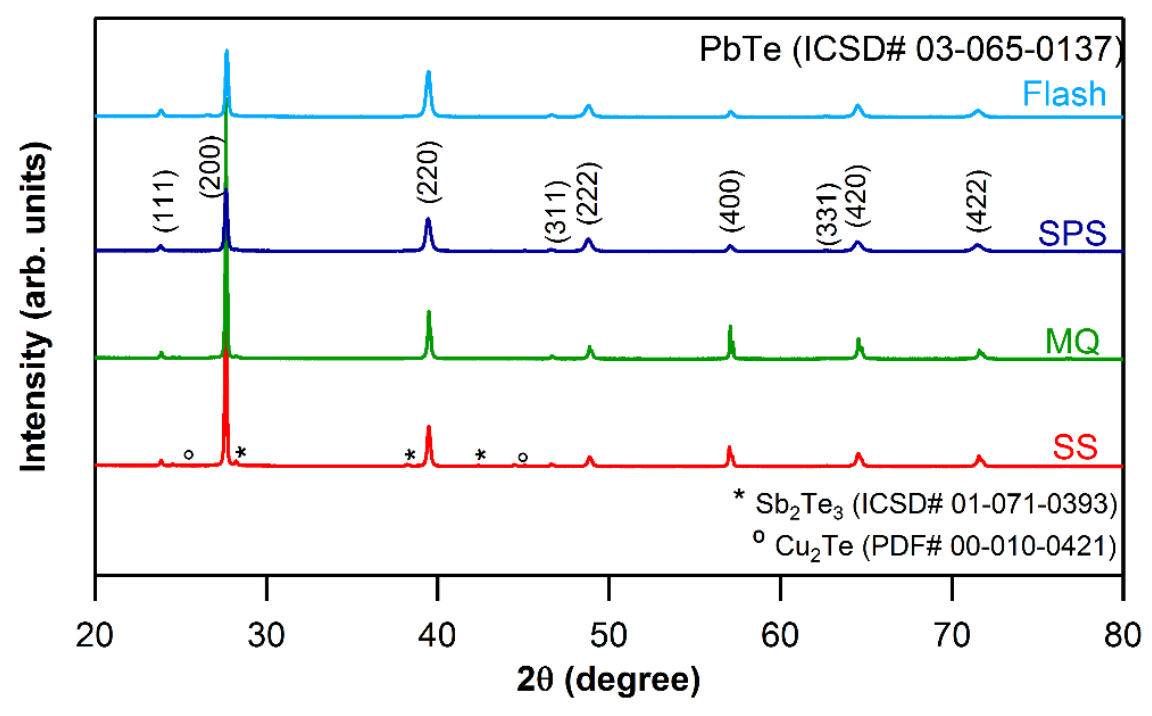


Figure 2. XRD patterns for different $\mathrm{CUPb}_{18} S \mathrm{~S} T \mathrm{Te}_{20}$ samples. For convenience, the Hybrid Flash-SPS sample is simply referred as 'flash' in all the figure captions in this paper.

The lattice parameter value for all the samples is given in Table 1. The Cu-substituted samples $\left(\mathrm{CuPb}_{18} \mathrm{SbTe}_{20}\right)$ had a smaller lattice parameter value compared to the literature on $\mathrm{AgPb}_{18} \mathrm{SbTe}_{20}$. This is unsurprising given the smaller atomic radius of $\mathrm{Cu}$ compared to $\mathrm{Ag}$.

Table 1. Lattice parameter values for the samples of composition CUPb ${ }_{18} \mathrm{SbTe}_{20}$ prepared by different synthesis routes and $\mathrm{AgPb}_{18} \mathrm{SbTe}_{20}$

\begin{tabular}{|c|c|c|c|}
\hline Composition & Synthesis Route & Sample Notation & $\begin{array}{c}\text { Lattice parameter, } \\
\text { a }(\AA)\end{array}$ \\
\hline \multirow{3}{*}{$\mathrm{CuPb}_{18} \mathrm{SbTe}_{20}$} & Slow cooling & SS & $6.4525(8)$ \\
\cline { 2 - 4 } & Melt quenching & MQ & $6.4499(5)$ \\
\cline { 2 - 4 } & Spark Plasma Sintering & SPS & $6.4542(3)$ \\
\cline { 2 - 4 } & Hybrid Flash-Spark Plasma Sintering & $\begin{array}{c}\text { Hybrid Flash-SPS (in text) } \\
\text { or 'Flash' (in figures) }\end{array}$ & $6.4536(4)$ \\
\hline $\mathrm{AgPb}_{18} \mathrm{SbTe}_{20}$ & Any synthesis route & LAST & $6.46^{62}, 6.54^{57}$ \\
\hline
\end{tabular}

The temperature-dependent total thermal conductivity, $\kappa_{\mathrm{tot}}$ derived from $D$ and $C_{p}$ using equation (5) is presented in Figure 3a. All of the $\mathrm{CuPb}_{18} \mathrm{SbTe}_{20}$ samples showed relatively similar thermal conductivity, with strong negative temperature dependence. The copper substitution altered very little the thermal conductivity compared to $\mathrm{AgPb}_{18} \mathrm{SbTe}_{20},{ }^{48}$ however, there were some differences due to the different synthesis routes.
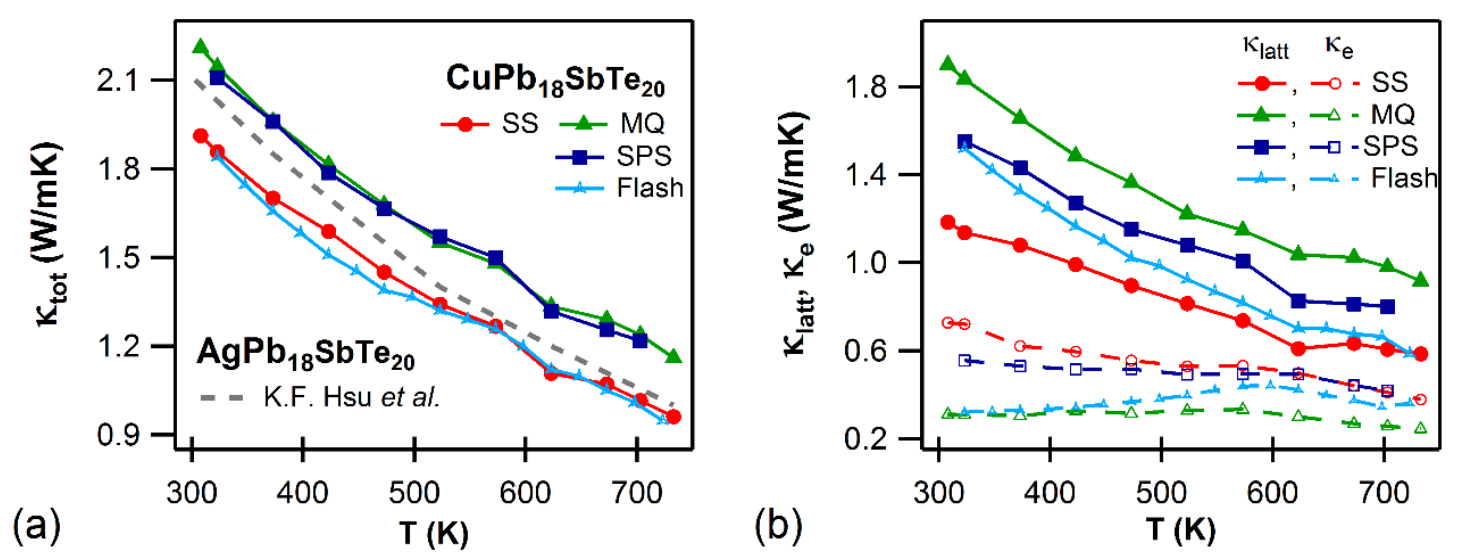

Figure 3. Thermal transport properties - (a) comparison of the total thermal conductivities, $\kappa_{\text {tot }}$ of different $\mathrm{CuPb}_{18} \mathrm{SbTe}_{20}$ samples vs $\mathrm{AgPb}_{18} \mathrm{SbTe}_{20}$ (b) lattice, $\kappa_{\text {latt }}$ and electronic, $\kappa_{e}$ contributions to thermal transport 
of different $\mathrm{CuPb}_{18} \mathrm{SbTe}_{20}$ samples. The solid lines in Figure 3(b) represent $\kappa_{\text {latt }}$ and the dashed lines represent $\kappa_{e}$.

The calculated temperature-dependent Lorenz numbers for all the samples were in the range of $1.68 \mathrm{x}$ $10^{-8}$ to $1.97 \times 10^{-8} \mathrm{~W} \Omega \mathrm{K}^{-2}$ and are lower than the metallic limit of $2.45 \times 10^{-8} \mathrm{~W} \Omega \mathrm{K}^{-2}$ (SI, Figure S4).

The $\mathrm{CuPb}_{18} \mathrm{SbTe}_{20}$ samples exhibited a low lattice thermal contribution of $<1 \mathrm{~W} / \mathrm{mK}$ at high temperatures (above $650 \mathrm{~K}$ ), as shown in Figure 3b. Klatt for the slow cooled (SS) sample and the sintered samples (both SPS and flash) were somewhat lower than for the sample prepared by rapid quenching of the melt (MQ). Both the slow cooled (SS) and the flash sintered samples demonstrated an ultra-low Klatt $\sim 0.58 \mathrm{~W} / \mathrm{mK}$ at $700 \mathrm{~K}$, which is comparable with literature values of LAST alloys prepared by different techniques. $50,52,62$ The low $\kappa_{\text {latt }}$ values of $\mathrm{AgPb}_{18} \mathrm{SbTe}_{20}$ in the literature were widely reported to be due to the effect of phonon scattering. The scattering defects have been hypothesized to be either the presence of strain fields or endotaxially embedded nanodots (rich in $\mathrm{Ag}$ and $\mathrm{Sb}$ ) in the PbTe matrix. These precipitates are strongly dependent on the annealing conditions and synthesis routes used. ${ }^{48,53-57}$ To shed some light on the reasons for the origin of ultra-low $\kappa_{\text {latt }}$ in $\mathrm{CuPb}_{18} \mathrm{SbTe}_{20}$ samples, a detailed TEM analysis was carried out to examine their nanostructure. The slow cooled (SS) sample was chosen for the TEM study, as it exhibits the lowest $\kappa_{\text {latt }}$ in the entire temperature range from $300-725 \mathrm{~K}$.

Figure $4 \mathrm{a}$ is a typical low-resolution image of $\mathrm{CuPb}_{18} \mathrm{SbTe}_{20}(\mathrm{SS})$, and it shows a distribution of Cu-rich nanoprecipitates with a uniform size range of 20-30 nm in the PbTe matrix. Besides these nano-inclusions, there was also a high number density of dislocations, which are known to scatter phonons via distinct mechanisms ${ }^{80}$ (Figure $4 \mathrm{~b}$ ). These nanoscale artifacts obviously generate constraints and deformation of the PbTe lattice, as seen from the high contrast image in Figure 4c. Each micro/nano scale feature can potentially scatter different frequency heat-carrying phonons. For instance, atomic-scale solid-solution point defects scatter short wavelength phonons with a mean free path (MFP) of less than $5 \mathrm{~nm}$, nanoscale precipitates scatter medium MFP phonons between $5-100 \mathrm{~nm}$, and mesoscale grain structures scatter long MPF phonons of $0.1-1.0 \mu \mathrm{m} .{ }^{81}$ At room temperature, $86 \%$ of $\kappa_{\text {latt }}$ of PbTe is found to be contributed by phonon modes with MFP of less than $100 \mathrm{~nm}$ and their contribution is increased to $93 \%$ at $600 \mathrm{~K}^{.82} \mathrm{In}$ $\mathrm{CuPb}_{18} \mathrm{SbTe}_{20}$ (SS), the Cu-rich nanoprecipitates $(20-30 \mathrm{~nm})$ are to likely dominate phonon scattering due to the large mass difference between the precipitate and the matrix, especially targeting the medium wavelength phonons. ${ }^{81,83}$ The SAED pattern oriented along the $\{-110\}$ plane of the lattice, with an aperture including reflections from the precipitates and the matrix region, as shown in Figure 4, was indexed based on a cubic rock-salt PbTe structure. The exact composition of the individual precipitates could not be 
determined owing to their overlap with the matrix. Figures $4 \mathrm{e}$, $\mathrm{f}$ suggested the presence of different kinds of precipitate-matrix interface (both coherent and incoherent interfaces) in this sample. Except for the presence of weak reflections from the $\mathrm{Cu}$-rich precipitates in the aperture for diffraction, no extra reflections or split spots were observed, suggesting an endotaxial arrangement of the precipitates within the matrix. ${ }^{12,84}$ The high resolution image along the $<002>$ direction, as in Figure $4 \mathrm{e}$, shows a coherent interface (no disorder) between the nano-inclusion and the matrix. But in some other regions (Figure 4f), not much noticeable high magnification contrasts from the precipitates or their strain field was observed, so it is possible that the precipitates might also have a random orientation. The dark contrast inclusion (Figure 4f) clearly showed two domains - the one which showed Moiré fringes (upper domain, noted as 'i') and the other which did not present any particular contrast (lower domain, noted as 'ii'). Moiré artifacts were observed at the interface (incoherent) as some of the precipitates were not oriented in the same $<002>$ direction of the PbTe lattice. These fringes were formed at the interface between two sets of lattice planes (overlap of matrix and nano-scale precipitates). A strong Moiré pattern, like that seen in Figure 4f, required the two lattices to have a small relative rotating angle and very similar periodicity, ${ }^{14}$ which provides sufficient atomic strains to scatter the heat carrying phonons. Hence it is clear that the medium mean free path phonons, the dominant contributor to the lattice thermal conductivity, are scattered by the nanoscale dislocations together with the high density of Cu-rich nano-inclusions. 

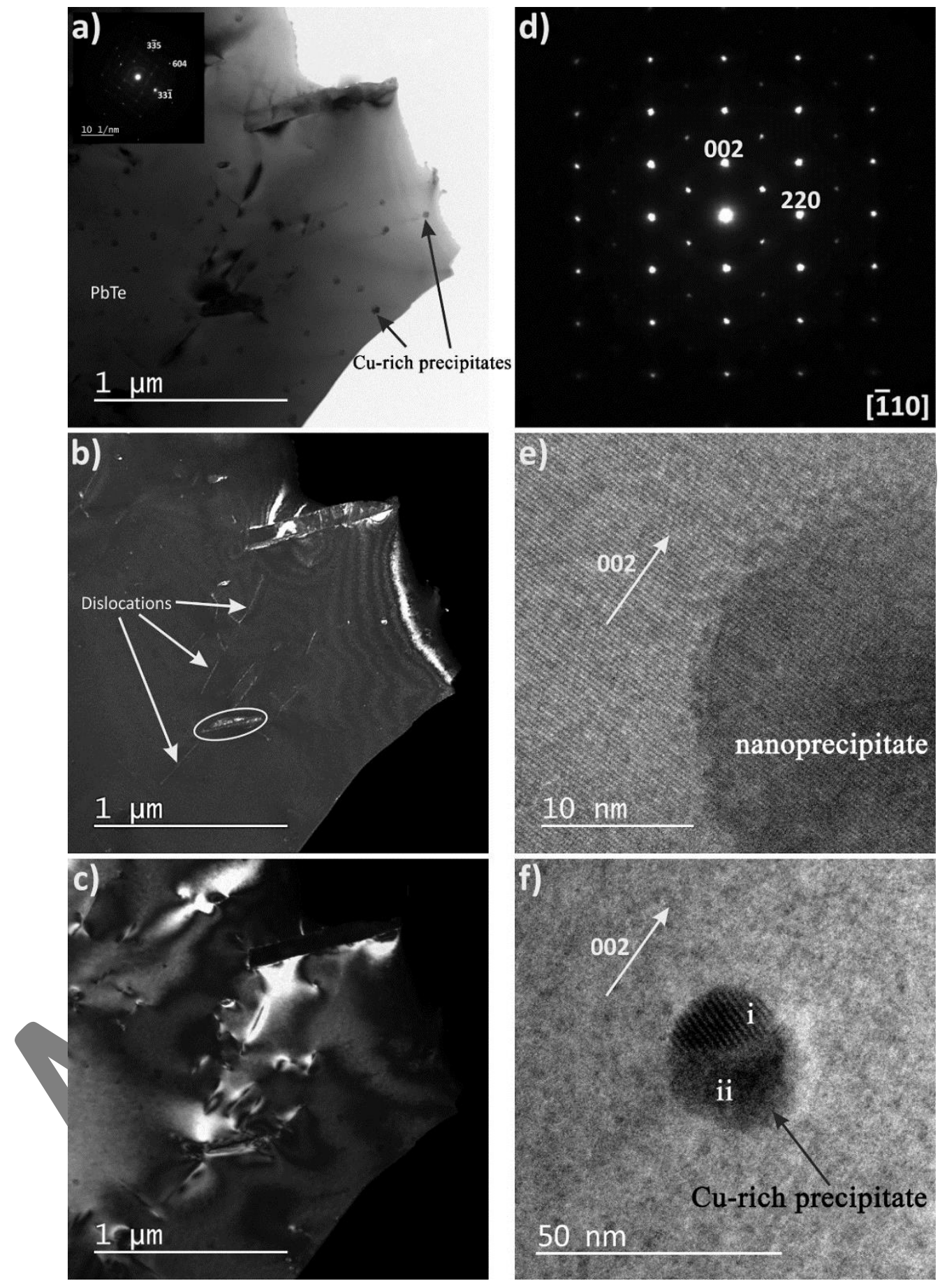

Figure 4. a) Bright Field (BF) image of $\mathrm{CuPb}_{18} \mathrm{SbTe}_{20}$ (SS) thin sample. Inset shows the diffraction pattern, b) Dark Field (DF) image made with the <3-35> reflection depicting the dislocations, c) DF image made with the <33-1> reflection, d) Diffraction pattern along the [-110] zone axis, e) High magnification image showing the interface between the PbTe matrix and a Cu-rich nano-inclusion. f) High magnification image of the nanoprecipitate showing Moiré fringes in the upper part of the dark contrast domain (marked as i). 
The high number of nanoprecipitate-matrix interfaces produces an effective barrier to heat carrying phonon transport in the bulk sample. ${ }^{81}$ Inhomogeneities within the matrix effectively reduce the lattice contribution, particularly when there is atomic reorganization to form thermodynamically stable nanostructures. ${ }^{80}$ All these factors contributed for the $\mathrm{CuPb}_{18} \mathrm{SbTe}_{20}$ sample prepared by slow cooling for manifesting an ultra-low $\kappa_{\text {latt. }}$. The same can also be said for the relatively low $\kappa_{\text {latt }}$ of the sintered samples, as current assisted sintering is widely known to produce nanostructured materials. ${ }^{10,85,86}$ However, melt quenching normally suppresses the formation of nano-precipitates. This is because there is typically insufficient time for atoms of any species to diffuse towards a nucleation point before the material has cooled enough (diffusion is too slow). This explains why the MQ sample had the highest lattice thermal transport (Figure $3 b$ ), as it has the least nano-precipitates.

Though the size of the precipitates, type of precipitate-matrix interfaces, and other nanoscale features for $\mathrm{CuPb}_{18} \mathrm{SbTe}_{20}$ reported in this work are different from those reported for $\mathrm{AgPb}_{18} \mathrm{SbTe}_{20}$ by Kanatzidis et al., $48,53,58,62$ the resulting thermal properties are very similar. This implies that one of these mechanisms could dominate the behavior, the others being far less important.

Based on the processing route, the $\mathrm{CuPb}_{18} \mathrm{SbTe}_{20}$ samples also had notable differences in microstructure as well as nanostructure. In fact the different microstructures clearly explains the difference in lattice conductivity between the hybrid flash-SPS sample and the conventional SPS sample (Figure 3). The microstructure of the SPS sample (Figure 5a) shows a transgranular failure with large grains $(100 \mu \mathrm{m})$ and no porosity. Whereas the microstructure of the hybrid flash-SPS sample (Figure 5b, c) contained a large number of smaller grains $(1-10 \mu \mathrm{m})$ surrounding larger grains $(50 \mu \mathrm{m})$, with porosity between the smaller grains. The ultra-fast sintering rate helped to reduce the grain growth during flash processing, at the expense of some micro-porosity. Reducing the grain size enhances the boundary scattering of heat carrying phonons at the intergrain region. Usually, the nanostructures produced by conventional processing techniques can scatter the majority of the short and medium MPF phonons, but a notable fraction of the remaining phonons (long MFP phonons) are not scattered. The mesoscale grain structures obtained by hybrid flash-SPS processing can scatter those long wavelength phonons. Thus hybrid flashSPS processing produced a 'multi-scale hierarchical architectures' (panoscopic approach), ${ }^{81}$ which can scatter a broader spectrum of heat carrying phonons. This along with the presence of micro-voids in their microstructure helped reducing the thermal conductivity of flash sintered sample. 

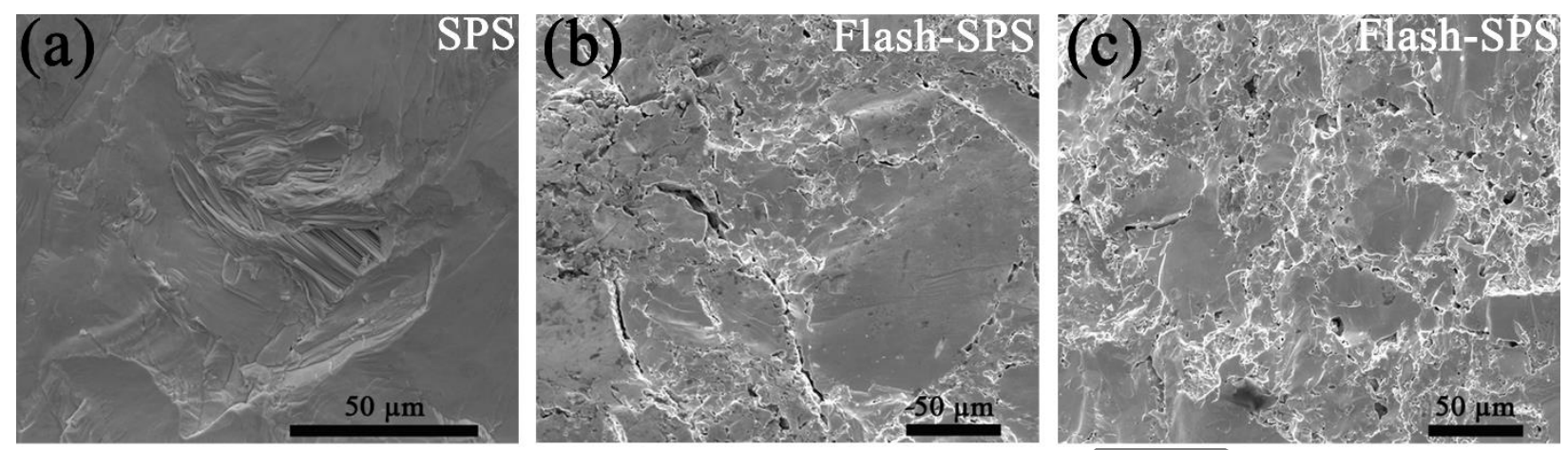

Figure 5. SEM images showing the microstructures at the fractured surface of (a) SPS sample with larger grains, (b, c) hybrid flash-SPS sample showing micro-porous voids and a mixture of larger and smaller grains.

The results from the Hall measurement tabulating carrier concentration, $n$, and mobility, $\mu_{c}$, are presented in Table 2. For all of the samples, including the literature on $\mathrm{AgPb}_{18} \mathrm{SbTe}_{20}$, the Hallvoltage was negative, meaning electrons were the major charge carriers ( $n$-type).

Table 2. Hall measurement results (at $300 \mathrm{~K}$ ) of carrier concentration, mobility, and computed effective mass for $\mathrm{MPb}_{18} \mathrm{SbTe}_{20}(\mathrm{M}=\mathrm{Cu}, \mathrm{Ag})$ samples.

\begin{tabular}{|cccc|}
\hline Sample & $\begin{array}{c}\text { Carrier Concentration, } \boldsymbol{n} \\
\left(\mathrm{cm}^{-3}\right)\end{array}$ & $\begin{array}{c}\text { Carrier Mobility, } \boldsymbol{\mu}_{\mathrm{c}} \\
\left(\mathrm{cm}^{2} \mathrm{~V}^{-1} \mathrm{~s}^{-1}\right)\end{array}$ & $\begin{array}{c}\text { Effective mass, } \boldsymbol{m}^{*} \\
\left(\mathrm{~m}_{\mathrm{e}}\right)\end{array}$ \\
$\mathrm{SS}$ & $1.75 \times 10^{19}$ & 695.85 & 0.30 \\
$\mathrm{MQ}$ & $2.32 \times 10^{19}$ & 180.31 & 0.41 \\
SPS & $1.51 \times 10^{19}$ & 523.54 & 0.39 \\
Hybrid Flash-SPS & $0.58 \times 10^{19}$ & 520.89 & 0.24 \\
AgPb ${ }_{18}$ SbTe $_{20}$ & $0.54 \times 10^{19}$ & 778 & 0.24 \\
(Han et al. [55]) & & & \\
\hline
\end{tabular}

The electrical transport properties are presented in Figure 6. The electrical conductivity of the Cu-doped samples were almost comparable with the Ag-doped LAST alloys (Figure 6a), especially at higher temperatures as the Cu samples were less temperature dependent. At room temperature, the SS and SPS samples had higher $\sigma$ compared to the MQ sample due to their higher charge carrier mobilities. The higher $\sigma$ might also have been due to additional contributions from the more conductive secondary phases, especially in the SS sample. The transport properties of the constituent phases in the SS sample are 
tabulated in SI (Table S2). The electrical and thermal transport are also known to undergo a significant change due to the nanoscale precipitation. ${ }^{80,87}$ Due to its low charge carrier density, the hybrid flash-SPS sample exhibited a lower $\sigma$. Due to ultra-fast heating and short processing time during hybrid-flash SPS, there is not much sufficient time for the sample to recrystallize and the dopants may not be evenly distributed and possibly might have moved from their lattice positions. Such changes in the electronic crystal structural arrangements might affect the charge carrier density. More in-depth studies are required to understand the mechanisms and the structural changes that happens during flash sintering. It must be noted that the carrier mobility was not significantly affected by flash processing (Table 2). In the MQ sample, the significant drop in electron mobility could be explained by alloy scattering, ${ }^{88}$ the electrons are scattered by the lattice distortions produced by the solid solution atoms. The MQ sample had the fewest precipitates, so must have had most solute atoms in the lattice. Though the carrier concentration was comparably high, the low carrier mobility caused the MQ sample to exhibit low $\sigma$. This explains the low $\kappa_{\mathrm{e}}$ value for $\mathrm{MQ}$ sample, as $\kappa_{\mathrm{e}}$ was calculated from $\sigma$ using the equation 6.
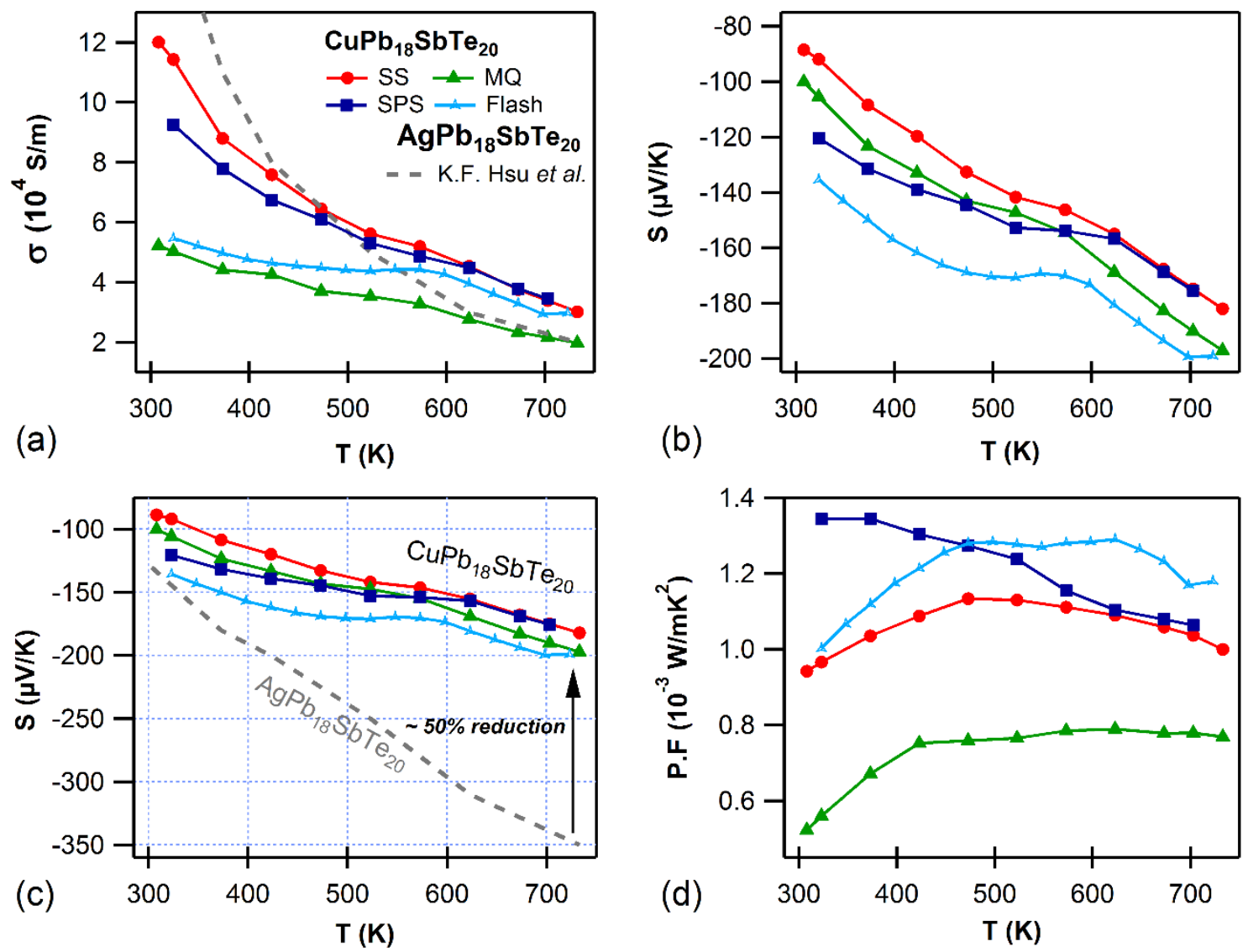
Figure 6. Temperature-dependent electrical transport properties for $\mathrm{CuPb}_{18} \mathrm{SbTe}_{20}$ prepared by different synthesis routes - (a) electrical conductivity $(\sigma)$, (b) Seebeck coefficient (S), (c) comparison of thermopower with $\mathrm{AgPb}_{18} \mathrm{SbTe}_{20}$, and (d) Power factor $\left(\mathrm{PF}=\mathrm{S}^{2} \sigma\right)$. Color code legend in (a) applies to all the plots here.

The continuous increase of the Seebeck coefficient for $\mathrm{CuPb}_{18} \mathrm{SbTe}_{20}$, as shown in Figure $6 \mathrm{~b}$, and the monotonic decrease in $\sigma$ with increasing temperature suggests degenerate semiconducting behavior. The negative Seebeck coefficient of all the samples confirmed that $n$-type charge carriers dominated. The $S$ values were coherent with the carrier densities obtained from the Hall measurement, i.e., congruent with $S \propto 1 / n$ relation. The only exception to this relation was the MQ sample, however such anomalous changes in the carrier density are difficult to explain and have been observed in few such materials. ${ }^{89-91}$ There was no significant variation in $S$-values between the samples of $\mathrm{CuPb}_{18} \mathrm{SbTe}_{20}$ prepared by SS, MQ and SPS. But the thermopower of the flash sample fares well compared to the other synthesis routes and it reaches a maximum thermopower of $\sim-200 \mu \mathrm{V} / \mathrm{K}$ at $700 \mathrm{~K}$. The low $\sigma$ of $\mathrm{MQ}$ sample affected considerably its thermoelectric power factor, as shown in Figure $6 \mathrm{~d}$. At temperatures $>450 \mathrm{~K}$, the flash sample outperformed the others in power factor values. It seems likely that the hybrid flash-SPS sintering process helps to achieve a better trade-off between $\sigma$ and $S$, as well as optimizing the charge carrier density and mobility. An intriguing aspect is that the $S$-values for $\mathrm{CuPb}_{18} \mathrm{SbTe}_{20}$ were much lower (almost $50 \%$ reduction at high temperature) than those for its $\mathrm{Ag}$ counterpart, i.e., $\mathrm{AgPb}_{18} \mathrm{SbTe}_{20}$, as illustrated in Figure 6c. In order to understand the origin of the huge difference in $\mathrm{S}$-values between $\mathrm{CuPb}_{18} \mathrm{SbTe}_{20}$ and $\mathrm{AgPb}_{18} \mathrm{SbTe}_{20}$, despite both compositions having comparable electrical and thermal conductivities, DFT calculations were performed to compare their band structures to get a clearer picture.

The band structures of the $\mathrm{MPb}_{18} \mathrm{SbTe}_{20}(\mathrm{M}=\mathrm{Ag}, \mathrm{Cu})$ compounds along the high symmetry lines of the Brillouin zone (supercell) are shown in Figure 7. Both compounds were computed to be semiconductor in character and were almost identical. They both exhibited a direct energy band gap. This energy band gap $\left(E_{\mathrm{g}}\right)$ between the valence and the conduction bands was much smaller for $\mathrm{CuPb}_{18} \mathrm{SbTe}_{20}$ (about $0.02 \mathrm{eV}$ ) when compared to that of $\mathrm{AgPb}_{18} \mathrm{SbTe}_{20}(0.1 \mathrm{eV})$. The computed band structure and the $E_{\mathrm{g}}$ value for the LAST alloy are in agreement with the literature. ${ }^{62}$ Goldsmid and Sharp ${ }^{92}$ derived an approximate expression for the maximum thermopower of a band material, $S_{\max } \approx E_{\mathrm{g}} / 2 e T_{\max }$, where $e$ is the elemental charge and $T_{\max }$ is the absolute temperature where the maximum thermopower is observed. According to this relation, the Seebeck coefficient of a semiconducting compound varies as the band gap, and this explains the reason for a decreased thermopower for $\mathrm{Cub}_{18} \mathrm{SbTe}_{20}\left(E_{\mathrm{g}} \sim 0.02 \mathrm{eV}\right)$ when compared to $\mathrm{AgPb}_{18} \mathrm{SbTe}_{20}\left(E_{\mathrm{g}} \sim 0.1 \mathrm{eV}\right)$. The energy differences between the heavy and light bands were lower in 
$\mathrm{Cub}_{18} \mathrm{SbTe}_{20}$ (Figure 7), and this explains the reason for higher effectives masses (Table 2) for $\mathrm{Cub}_{18} \mathrm{SbTe}_{20}$ when compared to $\mathrm{AgPb}_{18} \mathrm{SbTe}_{20}$.
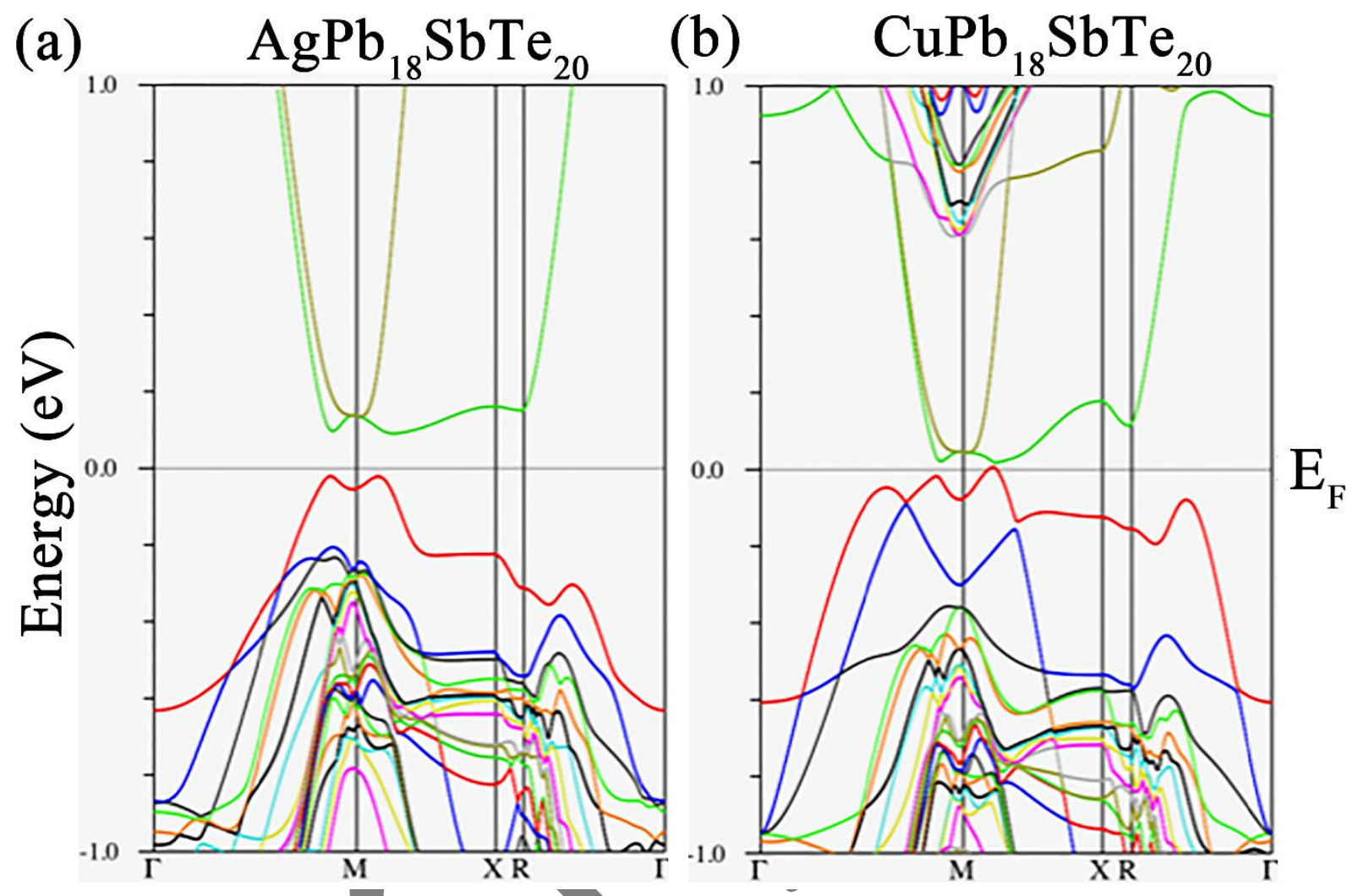

Figure 7. Electronic band structures computed for $M P b_{18} S_{b T e} 0(M=C u, A g)$. To compare the band structures, the same supercell was considered. Coordinates of high symmetry k-points: $\Gamma=(0,0,0), M=$ $(1 / 2,1 / 2,0), X=(0,1 / 2,0)$, and $R=(0,1 / 2,1 / 2)$

Isoelectronic $\mathrm{MPb}_{18} \mathrm{SbTe} \mathrm{e}_{20}(\mathrm{M}=\mathrm{Cu}, \mathrm{Ag}, \mathrm{Au})$ compounds were studied in silico. The calculated thermopower (at $300 \mathrm{~K}$ and $800 \mathrm{~K}$ ) as a function of the chemical potential $(\mu)$ for $\mathrm{MPb}_{18} \mathrm{SbTe}_{20}(\mathrm{M}=\mathrm{Cu}, \mathrm{Ag}, \mathrm{Au}$ ) is sketched in Figure 8. The computed Seebeck coefficient, at both lower and higher temperatures, for $\mathrm{CuPb}_{18} \mathrm{SbTe}_{20}$ was lower than for $\mathrm{AgPb}_{18} \mathrm{SbTe}_{20}$, consistent with the findings from their band structures (Figure 7) and their experimental results (Figure 6c). To complete the comparison on the coinage series, the computation of the transport properties were extended to the gold analogue as well ( $\left.\mathrm{AuPb}_{18} \mathrm{SbTe}_{20}\right)$. For this purpose, the same supercell was considered with Au clusters, as like $\mathrm{Cu}$ and $\mathrm{Ag}$. It is noteworthy to mention that, irrespective of the carrier concentration, the Seebeck coefficient was higher for $\mathrm{AgPb}_{18} \mathrm{SbTe}_{20}$ (at both lower and higher temperatures) compared to its gold and copper congeners, as depicted in Figure 8. 


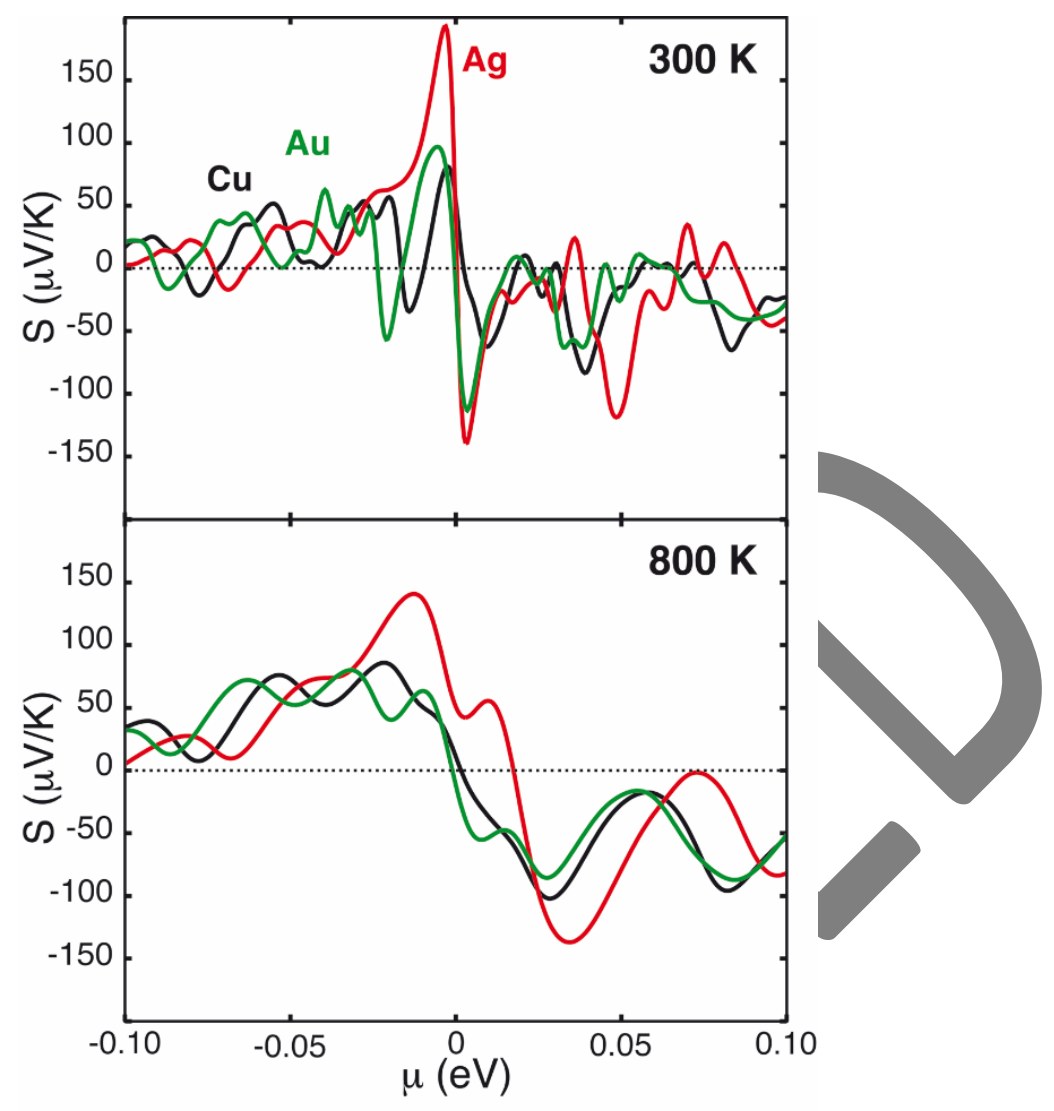

Figure 8. Thermopower as a function of the chemical potential $(\mu)$ computed at $300 \mathrm{~K}($ top) and $800 \mathrm{~K}$ (bottom) for $M P b_{18} S b T e_{20}(M=C u, A g, A u)$ models.

The thermoelectric figure of merit zT as a function of temperature, calculated from the electrical transport and thermal conductivity data, as in equation (1) is shown in Figure 9. The maximum $z T$ achieved for $\mathrm{CuPb}_{18} \mathrm{SbTe}_{20}$ is $\sim 0.9$ at $723 \mathrm{~K}$ was from the hybrid flash-SPS sample, followed by the SS sample with $z T \sim$ 0.8 at $723 \mathrm{~K}$, while the SPS and MQ samples had slightly lower $z T$ values of $\sim 0.6$ at $700 \mathrm{~K}$ and $\sim 0.5$ at 723 $\mathrm{K}$, respectively. The higher ZT for the hybrid flash-SPS samples was due to the increased power factor and decreased thermal conductivity.

It is established that higher the ratio of the carrier mobility to lattice thermal conductivity, the greater the $\mathrm{zT}^{93}$ Normally, there is a trade-off when alloying a material. The lattice thermal conductivity ( $\kappa_{\text {att }}$ ) is decreased due to scattering from impurities, but that also reduces the carrier mobility $\left(\mu_{c}\right)$, meaning limited change in $z T$. An improvement in $z T$ for an alloy system occurs only when $\kappa_{\text {latt }}$ is reduced by a significant factor with little or no degradation of $\mu_{\mathrm{c}}$. The slow cooled sample (SS) and conventional SPS sample exhibit higher $\mu_{\mathrm{c}} / \kappa_{\text {latt }}$ ratio, thanks to their precipitate scattering, however their higher carrier 
concentration reduces their thermopower significantly. But with the hybrid flash-SPS sintering process, we have demonstrated that it is possible to optimize the charge carrier density, and at the same time benefit from the decreased lattice thermal conductivity without significantly affecting the carrier mobility (i.e., higher $\mu_{\mathrm{c}} / \kappa_{\text {latt }}$ ratio). Moving forward, the hybrid flash-SPS technique can potentially be used as a strategic processing route to decouple electrical and thermal transport properties to produce high $z T$ materials.
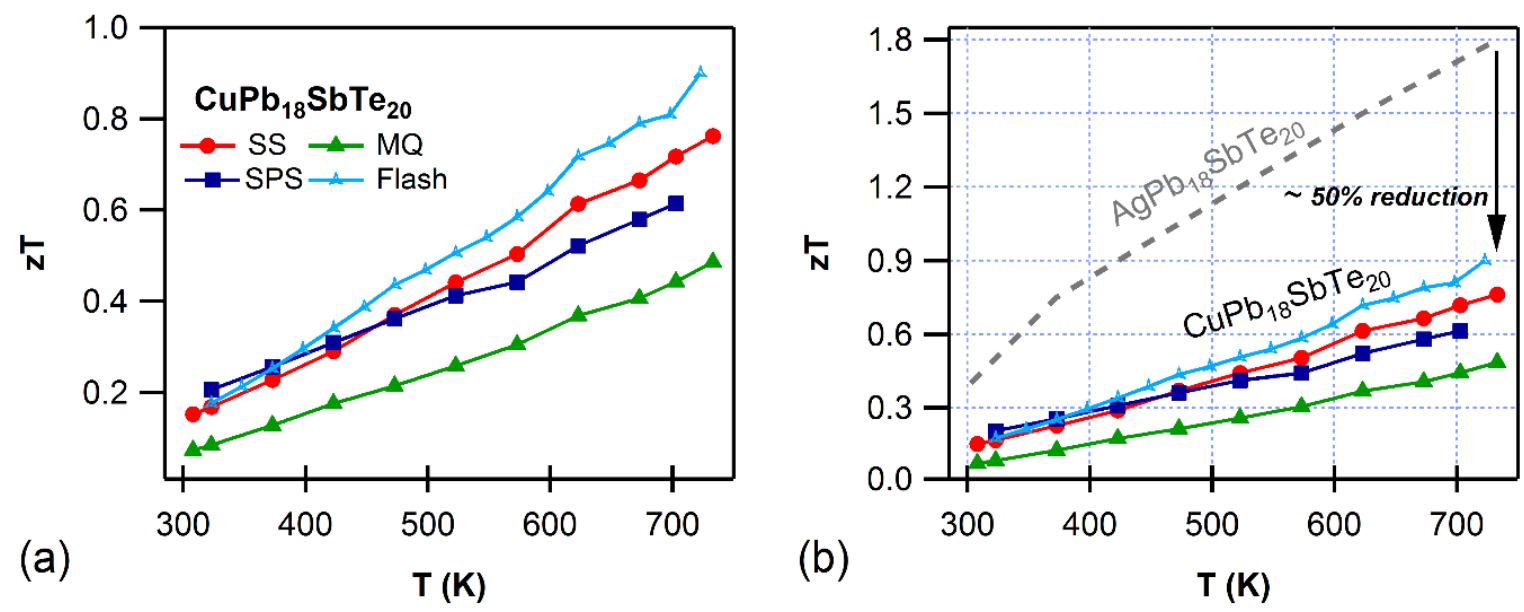

Figure 9. Temperature-dependent thermoelectric figure of merit, $z T-(a)$ for $\mathrm{CuPb}_{18} \mathrm{SbTe}_{20}$ samples that were prepared by different synthesis routes, (b) for different CuPb ${ }_{18} S b T e_{20}$ samples vs AgPb ${ }_{18} S b T e_{20}$.

In any case, the larger picture is that, irrespective of the route of synthesis, $\mathrm{AgPb}_{18} \mathrm{SbTe}_{20}$ exhibits much higher $z T$ compared to its $\mathrm{Cu}$-counterpart that is reported in this paper. The $z T$ of $\mathrm{CuPb}_{18} \mathrm{SbTe}_{20}$ at higher temperatures $(>700 \mathrm{~K})$ is more than $50 \%$ lower than the $z T$ of LAST-18 composition, as illustrated in Figure $9 b$. Such a disparity in $z T$ is primarily ascribed to differing power factor values, caused primarily by the Seebeck coefficient. Our theoretical analysis, described earlier in this paper, clearly reveals the rationale for the origin of divergence in the Seebeck coefficient values for $\mathrm{CuPb}_{18} \mathrm{SbTe}_{20}$ and $\mathrm{AgPb}_{18} \mathrm{SbTe}_{20}$.

\section{Conclusion}

In this paper, we systematically investigated four different routes of synthesizing high quality crystalline samples of $\mathrm{CuPb}_{18} \mathrm{SbTe}_{20}$. The thermoelectric properties of the different $\mathrm{CuPb}_{18} \mathrm{SbTe}_{20}$ samples were compared with their well-studied Ag counterpart, i.e., $\mathrm{AgPb}_{18} \mathrm{SbTe}_{20}$. Replacement of $\mathrm{Ag}$ by $\mathrm{Cu}$ in LAST alloys, despite the differences in their nanoscale architectures, did not significantly affect their thermal 
conductivity. $\mathrm{CuPb}_{18} \mathrm{SbTe}_{20}$ exhibited $\kappa_{\text {tot }}$ values of less than $1.2 \mathrm{~W} / \mathrm{mK}$ at T $>700 \mathrm{~K}$, comparable with that of $\mathrm{AgPb}_{18} \mathrm{SbTe}_{20}$. In particular, both the slow cooled sample and the hybrid flash sintered sample had an ultra-low $\kappa_{\text {latt }}$ of $\sim 0.58 \mathrm{~W} / \mathrm{mK}$ at $723 \mathrm{~K}$, primarily due to phonon scattering that arose from the presence of nanoscale dislocations together with a high density of Cu-rich nano-inclusions in the SS sample and reduced grain growth (meso-structuring) and porosity of the flash sintered sample. In addition, the electrical conductivities of the $\mathrm{CuPb}_{18} \mathrm{SbTe}_{20}$ samples were also comparable with that of their $\mathrm{Ag}$ counterpart. Hybrid Flash-SPS processing provided a way to achieve a better trade-off between the transport properties by decreasing the carrier concentration and $\kappa_{\text {latt }}$ without degrading the carrier mobility, thus enabling a higher $z T \sim 0.9$ at $723 \mathrm{~K}$. However, the replacement of Ag with Cu was found to be detrimental to the overall thermoelectric figure of merit, as the $z T$ values of $\mathrm{CuPb}_{18} \mathrm{SbTe}_{20}$, irrespective of the route of synthesis, were drastically reduced when compared with $\mathrm{AgPb}_{18} \mathrm{SbTe}_{20}$. This stems foremost from the fact that the Seebeck coefficient values of $\mathrm{CuPb}_{18} \mathrm{SbTe}_{20}$ were almost $50 \%$ lower than that of $\mathrm{AgPb}_{18} \mathrm{SbTe}_{20}$, especially at higher temperatures. The electronic transport coefficients for $\mathrm{MPb}_{18} \mathrm{SbTe}_{20}(\mathrm{M}=\mathrm{Cu}, \mathrm{Ag}$ and $\mathrm{Au})$ calculated within the Boltzmann transport equation at $300 \mathrm{~K}$ and $800 \mathrm{~K}$, also reveal that the thermopower of Ag-doped material outshines that of the Au or Cu-doped ones, consistent with the experimental findings. With the aid of first-principles calculations, we have demonstrated that replacement by isovalent $\mathrm{Cu}$ for Ag in LAST alloys significantly modify their electronic band structure by decreasing the energy band gap, which unraveled the rationale for their decreased thermopower.

\section{Associated Content}
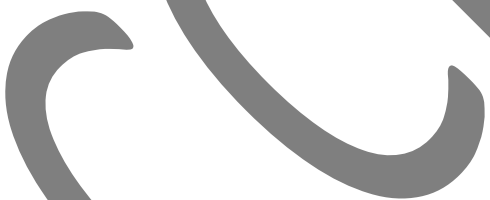

\section{Supporting Information}

Sintering configurations, transport properties of constituent phases, thermal diffusivity, and Lorenz number.

Acknowledgement: Financial support from the European Commission's Horizon 2020 research and innovation program under Marie Skłodowska-Curie GA. 642557 (CoACH-ETN); and microscopy platform of University of Rennes 1 (THEMIS-ScanMAT) and Dr. Sylvain Tricot (IPR Rennes) are also acknowledged. 


\section{References}

(1) Sootsman, J. R.; Chung, D. Y.; Kanatzidis, M. G. New and Old Concepts in Thermoelectric Materials. Angew. Chem. Int. Ed. 2009, 48 (46), 8616-8639.

(2) Dresselhaus, M. S.; Chen, G.; Tang, M. Y.; Yang, R. G.; Lee, H.; Wang, D. Z.; Ren, Z. F.; Fleurial, J.-P.; Gogna, P. New Directions for Low-Dimensional Thermoelectric Materials. Adv. Mater. 2007, 19 (8), 1043-1053.

(3) Szczech, J. R.; Higgins, J. M.; Jin, S. Enhancement of the Thermoelectric Properties in Nanoscale and Nanostructured Materials. J Mater Chem 2011, 21 (12), 4037-4055.

(4) Vaqueiro, P.; Powell, A. V. Recent Developments in Nanostructured Materials for HighPerformance Thermoelectrics. J. Mater. Chem. 2010, 20 (43), 9577-9584.

(5) LaLonde, A. D.; Pei, Y.; Wang, H.; Jeffrey Snyder, G. Lead Telluride Alloy Thermoelectrics. Mater. Today 2011, 14 (11), 526-532.

(6) Snyder, G. J.; Toberer, E. S. Complex Thermoelectric Materials. Nat. Mater. 2008, 7(2), 105-114.

(7) Li, J.-F.; Liu, W.-S.; Zhao, L.-D.; Zhou, M. High-Performance Nanostructured Thermoelectric Materials. NPG Asia Mater. 2010, 2 (4), 152-158.

(8) Hicks, L. D.; Dresselhaus, M. S. Effect of Quantum-Well Structures on the Thermoelectric Figure of Merit. Phys. Rev. B 1993, 47 (19), 12727-12731.

(9) Sootsman, J. R.; Kong, H.; Uher, C.; D’Angelo, J. J.; Wu, C.-1.; Hogan, T. P.; Caillat, T.; Kanatzidis, M. G. Large Enhancements in the Thermoelectric Power Factor of Bulk PbTe at High Temperature by Synergistic Nanostructuring. Angew. Chem. Int. Ed. 2008, 47 (45), 8618-8622.

(10) Biswas, K.; He, J.; Blum, I. D.; Wu, C.-I.; Hogan, T. P.; Seidman, D. N.; Dravid, V. P.; Kanatzidis, M. G. High-Performance Bulk Thermoelectrics with All-Scale Hierarchical Architectures. Nature 2012, 489 (7416), 414-418.

(11) Poudeu, P. F. P.; D’Angelo, J; Downey, A. D.; Short, J. L.; Hogan, T. P.; Kanatzidis, M. G. High Thermoelectric Figure of Merit and Nanostructuring in Bulk P-Type $\mathrm{Na}_{1-x} \mathrm{~Pb}_{\mathrm{m}} \mathrm{Sb}_{\mathrm{y}} \mathrm{Te}_{\mathrm{m}+2}$. Angew. Chem. Int. Ed. 2006, 45 (23), 3835-3839.

(12) Biswas, K.; He, J.; Zhang, Q.; Wang, G.; Uher, C.; Dravid, V. P.; Kanatzidis, M. G. Strained Endotaxial Nanostructures with High Thermoelectric Figure of Merit. Nat. Chem. 2011, 3 (2), 160166.

(13) Zhang, Q.; Chere, E. K.; Wang, Y.; Kim, H. S.; He, R.; Cao, F.; Dahal, K.; Broido, D.; Chen, G.; Ren, Z. High Thermoelectric Performance of $n-T_{y p e} \mathrm{PbTe}_{1-y} \mathrm{~S}_{y}$ Due to Deep Lying States Induced by Indium Doping and Spinodal Decomposition. Nano Energy 2016, 22 (Supplement C), 572-582.

(14) Lo, S.-H.; He, J.; Biswas, K.; Kanatzidis, M. G.; Dravid, V. P. Phonon Scattering and Thermal Conductivity in P-Type Nanostructured PbTe-BaTe Bulk Thermoelectric Materials. Adv. Funct. Mater. 2012, 22 (24), 5175-5184.

(15) Poudeu, P. F. P.; Guéguen, A.; Wu, C.-I.; Hogan, T.; Kanatzidis, M. G. High Figure of Merit in Nanostructured n-Type $\mathrm{KPb}_{\mathrm{m}} \mathrm{SbTe}_{\mathrm{m}+2}$ Thermoelectric Materials. Chem. Mater. 2010, 22 (3), 10461053.

(16) Zide, J. M. O.; Vashaee, D.; Bian, Z. X.; Zeng, G.; Bowers, J. E.; Shakouri, A.; Gossard, A. C. Demonstration of Electron Filtering to Increase the Seebeck Coefficient in InGaAs/InGaAlAs Superlattices. Phys. Rev. B 2006, 74 (20), 205335.

(17) Banik, A.; Shenoy, U. S.; Anand, S.; Waghmare, U. V.; Biswas, K. Mg Alloying in SnTe Facilitates Valence Band Convergence and Optimizes Thermoelectric Properties. Chem. Mater. 2015, 27 (2), 581-587.

(18) Pei, Y.; Shi, X.; LaLonde, A.; Wang, H.; Chen, L.; Snyder, G. J. Convergence of Electronic Bands for High Performance Bulk Thermoelectrics. Nature 2011, 473 (7345), 66-69. 
(19) Banik, A.; Shenoy, U. S.; Saha, S.; Waghmare, U. V.; Biswas, K. High Power Factor and Enhanced Thermoelectric Performance of SnTe-AgInTe 2 : Synergistic Effect of Resonance Level and Valence Band Convergence. J. Am. Chem. Soc. 2016, 138 (39), 13068-13075.

(20) Srinivasan, B.; Gautier, R.; Gucci, F.; Fontaine, B.; Halet, J.-F.; Cheviré, F.; Boussard-Pledel, C.; Reece, M. J.; Bureau, B. Impact of Coinage Metal Insertion on the Thermoelectric Properties of GeTe Solid-State Solutions. J. Phys. Chem. C 2018, 122 (1), 227-235.

(21) Zhang, Q.; Liao, B.; Lan, Y.; Lukas, K.; Liu, W.; Esfarjani, K.; Opeil, C.; Broido, D.; Chen, G.; Ren, Z. High Thermoelectric Performance by Resonant Dopant Indium in Nanostructured SnTe. Proc. Natl. Acad. Sci. U. S. A. 2013, 110 (33), 13261-13266.

(22) Carruthers, P. Theory of Thermal Conductivity of Solids at Low Temperatures. Rev. Mod. Phys. 1961, 33 (1), 92-138.

(23) Srinivasan, B.; Gucci, F.; Boussard-Pledel, C.; Cheviré, F.; Reece, M. I.; Tricot, S.; Calvez, L.; Bureau, B. Enhancement in Thermoelectric Performance of n-Type Pb-Deficit Pb-Sb-Te Alloys. J. Alloys Compd. 2017, 729 (Supplement C), 198-202.

(24) Chere, E. K.; Zhang, Q.; McEnaney, K.; Yao, M.; Cao, F.; Sun, J.; Chen, S.; Opeil, C.; Chen, G.; Ren, Z. Enhancement of Thermoelectric Performance in n-Type PbTe ${ }_{1-y} \mathrm{Se}_{y}$ by Doping $\mathrm{Cr}$ and Tuning Te:Se Ratio. Nano Energy 2015, 13 (Supplement C), 355-367.

(25) Zhao, W.; Wei, P.; Zhang, Q.; Dong, C.; Liu, L.; Tang, X. Enhanced Thermoelectric Performance in Barium and Indium Double-Filled Skutterudite Bulk Materials via Orbital Hybridization Induced by Indium Filler. J. Am. Chem. Soc. 2009, 131 (10), 3713-3720.

(26) Brown, S. R.; Kauzlarich, S. M.; Gascoin, F.; Snyder, G. J. Yb ${ }_{14} \mathrm{MnSb}_{11}$ : New High Efficiency Thermoelectric Material for Power Generation. Chem. Mater. 2006, 18 (7), 1873-1877.

(27) Toberer, E. S.; May, A. F.; Snyder, G. J. Zintl Chemistry for Designing High Efficiency Thermoelectric Materials. Chem. Mater. 2010, 22 (3), 624-634.

(28) Kauzlarich, S. M.; Brown, S. R.; Snyder, G. J. Zintl Phases for Thermoelectric Devices. Dalton Trans. 2007, No. 21, 2099-2107.

(29) Venkatasubramanian, R.; Siivola, E.; Colpitts, T.; O'Quinn, B. Thin-Film Thermoelectric Devices with High Room-Temperature Figures of Merit. Nature 2001, 413 (6856), 597-602.

(30) Gonçalves, A.P.; Lopes, E. B.; Rouleau, O.; Godart, C. Conducting Glasses as New Potential Thermoelectric Materials: The Cu-Ge-Te Case. J. Mater. Chem. 2010, 20 (8), 1516-1521.

(31) Lucas, P.; Conseil, C.; Yang, Z.; Hao, Q.; Cui, S.; Boussard-Pledel, C.; Bureau, B.; Gascoin, F.; Caillaud, C.; Gulbiten, O.; et al. Thermoelectric Bulk Glasses Based on the Cu-As-Te-Se System. J. Mater. Chem. A 2013, 1 (31), 8917-8925.

(32) Srinivasan, B.; Cui, S.; Prestipino, C.; Gellé, A.; Boussard-Pledel, C.; Ababou-Girard, S.; Trapananti, A.; Bureau, B.; Di Matteo, S. Possible Mechanism for Hole Conductivity in Cu-As-Te Thermoelectric Glasses; A XANES and EXAFS Study. J. Phys. Chem. C 2017, 121 (26), 1404514050.

(33) Srinivasan, B.; Boussard-Pledel, C.; Dorcet, V.; Samanta, M.; Biswas, K.; Lefèvre, R.; Gascoin, F.; Cheviré, F.; Tricot, S.; Reece, M.; et al. Thermoelectric Properties of Highly-Crystallized Ge-Te-Se Glasses Doped with Cu/Bi. Materials 2017, 10 (4), 328.

(34) Gonçalves, A. P.; Lopes, E. B.; Delaizir, G.; Vaney, J. B.; Lenoir, B.; Piarristeguy, A.; Pradel, A.; Monnier, J.; Ochin, P.; Godart, C. Semiconducting Glasses: A New Class of Thermoelectric Materials? J. Solid State Chem. 2012, 193, 26-30.

(35) Mori, T. Novel Principles and Nanostructuring Methods for Enhanced Thermoelectrics. Small 2017, 13 (45), 1702013.

(36) Takaki, H.; Kobayashi, K.; Shimono, M.; Kobayashi, N.; Hirose, K.; Tsujii, N.; Mori, T. Thermoelectric Properties of a Magnetic Semiconductor CuFeS2. Mater. Today Phys. 2017, 3, 8592. 
(37) Vandaele, K.; Watzman, S. J.; Flebus, B.; Prakash, A.; Zheng, Y.; Boona, S. R.; Heremans, J. P. Thermal Spin Transport and Energy Conversion. Mater. Today Phys. 2017, 1, 39-49.

(38) Ahmed, F.; Tsujii, N.; Mori, T. Thermoelectric Properties of $\mathrm{CuGa}_{1-\mathrm{x}} \mathrm{Mn}_{\mathrm{x}} \mathrm{Te}_{2}$ : Power Factor Enhancement by Incorporation of Magnetic lons. J. Mater. Chem. A 2017, 5 (16), 7545-7554.

(39) Chen, Z.-G.; Han, G.; Yang, L.; Cheng, L.; Zou, J. Nanostructured Thermoelectric Materials: Current Research and Future Challenge. Prog. Nat. Sci. Mater. Int. 2012, 22 (6), 535-549.

(40) Srinivasan, B.; Boussard-Pledel, C.; Bureau, B. Thermoelectric Performance of Codoped (Bi, In)GeTe and (Ag, In, Sb)-SnTe Materials Processed by Spark Plasma Sintering. Mater. Lett. 2018, 230, 191-194.

(41) Du, B.; Gucci, F.; Porwal, H.; Grasso, S.; Mahajan, A.; Reece, M. J. Flash Spark Plasma Sintering of Magnesium Silicide Stannide with Improved Thermoelectric Properties. J. Mater. Chem. C 2017, 5 (6), 1514-1521.

(42) Cologna Marco; Rashkova Boriana; Raj Rishi. Flash Sintering of Nanograin Zirconia in $<5 \mathrm{~s}$ at $850^{\circ}$ C. J. Am. Ceram. Soc. 2010, 93 (11), 3556-3559.

(43) Yu, M.; Grasso, S.; Mckinnon, R.; Saunders, T.; Reece, M. J. Review of Flash Sintering: Materials, Mechanisms and Modelling. Adv. Appl. Ceram. 2017, 116 (1), 24-60.

(44) Olevsky, E. A.; Rolfing, S. M.; Maximenko, A. L. Flash (Ultra-Rapid) Spark-Plasma Sintering of Silicon Carbide. Sci. Rep. 2016, 6, 33408.

(45) Biesuz, M.; Sglavo, V. M. Flash Sintering of Ceramics. J. Eur. Ceram. Soc. 2018, In Press.

(46) Grasso, S.; Kim, E.-Y.; Saunders, T.; Yu, M.; Tudball, A.; Choi, S.-H.; Reece, M. Ultra-Rapid Crystal Growth of Textured SiC Using Flash Spark Plasma Sintering Route. Cryst. Growth Des. 2016, 16 (4), 2317-2321.

(47) Grasso Salvatore; Saunders Theo; Porwal Harshit; Cedillos-Barraza Omar; Jayaseelan Daniel Doni; Lee William E.; Reece Mike John; Fahrenholtz W. Flash Spark Plasma Sintering (FSPS) of Pure ZrB2. J. Am. Ceram. Soc. 2014, 97 (8), 2405-2408.

(48) Hsu, K. F.; Loo, S.; Guo, F.; Chen, W.; Dyck, J. S.; Uher, C.; Hogan, T.; Polychroniadis, E. K.; Kanatzidis, M. G. Cubic AgPb $\mathrm{SbTe}_{2+m}$. Bulk Thermoelectric Materials with High Figure of Merit. Science 2004, 303 (5659), 818-821.

(49) Wang, H.; Li, J.-F.; Nan, C.-W.; Zhou, M., Liu, W.; Zhang, B.-P.; Kita, T. High-Performance $\mathrm{Ag}_{0.8} \mathrm{~Pb}_{18+\times} \mathrm{SbTe}_{20}$ Thermoelectric Bulk Materials Fabricated by Mechanical Alloying and Spark Plasma Sintering. Appl. Phys. Lett. 2006, 88 (9), 092104.

(50) Zhou, M.; Li, J.-F.; Kita, T. Nanostructured AgPb ${ }_{m} \mathrm{SbTe}_{\mathrm{m}+2}$ System Bulk Materials with Enhanced Thermoelectric Performance, J. Am. Chem. Soc. 2008, 130 (13), 4527-4532.

(51) Kanatzidis, M. G. Nanostructured Thermoelectrics: The New Paradigm? Chem. Mater. 2010, 22 (3), 648-659.

(52) Pei, J.; Zhang, B.-P.; Li, J.-F.; Liang, D.-D. Maximizing Thermoelectric Performance of $\mathrm{AgPb}_{\mathrm{m}} \mathrm{SbTe}_{\mathrm{m}+2}$ by Optimizing Spark Plasma Sintering Temperature. J. Alloys Compd. 2017.

(53) Cook, B. A.; Kramer, M. J.; Harringa, J. L.; Han, M.-K.; Chung, D.-Y.; Kanatzidis, M. G. Analysis of Nanostructuring in High Figure-of-Merit $\mathrm{Ag}_{1-\mathrm{x}} \mathrm{Pb}_{\mathrm{m}} \mathrm{SbTe}_{2+\mathrm{m}}$ Thermoelectric Materials. Adv. Funct. Mater. 2009, 19 (8), 1254-1259.

(54) Quarez, E.; Hsu, K.-F.; Pcionek, R.; Frangis, N.; Polychroniadis, E. K.; Kanatzidis, M. G. Nanostructuring, Compositional Fluctuations, and Atomic Ordering in the Thermoelectric Materials $\mathrm{AgPb}_{\mathrm{m}} \mathrm{SbTe}_{2+\mathrm{m}}$. The Myth of Solid Solutions. J. Am. Chem. Soc. 2005, 127 (25), 91779190.

(55) Ke, X.; Chen, C.; Yang, J.; Wu, L.; Zhou, J.; Li, Q.; Zhu, Y.; Kent, P. R. C. Microstructure and a Nucleation Mechanism for Nanoprecipitates in PbTe - AgSbTe. 2 . Phys. Rev. Lett. 2009, 103 (14), 145502. 
(56) Perlt, S.; Höche, T.; Dadda, J.; Müller, E.; Bauer Pereira, P.; Hermann, R.; Sarahan, M.; Pippel, E.; Brydson, R. Microstructure Analyses and Thermoelectric Properties of $\mathrm{Ag}_{1-\mathrm{x}} \mathrm{Pb}_{18} \mathrm{Sb}_{1+y} \mathrm{Te}_{20}$. J. Solid State Chem. 2012, 193 (Supplement C), 58-63.

(57) Arachchige, I. U.; Wu, J.; Dravid, V. P.; Kanatzidis, M. G. Nanocrystals of the Quaternary Thermoelectric Materials: $\mathrm{AgPb}_{\mathrm{m}} \mathrm{SbTe}_{\mathrm{m}+2}(\mathrm{~m}=1-18)$ : Phase-Segregated or Solid Solutions? Adv. Mater. 2008, 20 (19), 3638-3642.

(58) Bilc, D.; Mahanti, S. D.; Quarez, E.; Hsu, K.-F.; Pcionek, R.; Kanatzidis, M. G. Resonant States in the Electronic Structure of the High Performance Thermoelectrics $\mathrm{AgPb}_{\mathrm{m}} \mathrm{SbTe}_{2+\mathrm{m}}$ : The Role of Ag-Sb Microstructures. Phys. Rev. Lett. 2004, 93 (14), 146403.

(59) Zhang, Y.; Ke, X.; Chen, C.; Yang, J.; Kent, P. R. C. Nanodopant-Induced Band Modulation in $\mathrm{AgPb}_{m} \mathrm{SbTe}_{2+m}$-Type Thermoelectrics. Phys. Rev. Lett. 2011, 106 (20), 206601.

(60) Hazama, H.; Mizutani, U.; Asahi, R. First-Principles Calculations of Ag-Sb Nanodot Formation in Thermoelectric AgPb $\mathrm{SbTe}_{2+\mathrm{m}}(\mathrm{M}=6,14,30)$. Phys. Rev. B 2006, 73 (11), 115108.

(61) Ahn, K.; Li, C.; Uher, C.; Kanatzidis, M. G. Improvement in the Thermoelectric Figure of Merit by La/Ag Cosubstitution in PbTe. Chem. Mater. 2009, 21 (7), 1361-1367.

(62) Han, M.-K.; Hoang, K.; Kong, H.; Pcionek, R.; Uher, C.; Paraskevopoulos, K. M.; Mahanti, S. D.; Kanatzidis, M. G. Substitution of Bi for Sb and Its Role in the Thermoelectric Properties and Nanostructuring in $\mathrm{Ag}_{1-\mathrm{x}} \mathrm{Pb}_{18} \mathrm{MTe}_{20}(\mathrm{M}=\mathrm{Bi}, \mathrm{Sb})(\mathrm{x}=0,0.14,0.3)$. Chem. Mater, 2008, 20 (10), 3512-3520.

(63) Qian Zhang, Y. L. Increased Thermoelectric Performance by Cl Doping in Nanostructured $\mathrm{AgPb}_{18} \mathrm{SbSe}_{20-\mathrm{x}} \mathrm{Cl}_{\mathrm{x}}$. Nano Energy 2013, 2 (6), 1121-1127.

(64) Gucci, F.; Saunders, T. G.; Reece, M. J. In-Situ Synthesis of n-Type Unfilled Skutterudite with Reduced Thermal Conductivity by Hybrid Flash-Spark Plasma Sintering. Scr. Mater. 2018, 157, 5861.

(65) B. Srinivasan et al., Realizing a Stable High Thermoelectric $z T \sim 2$ over a Broad Temperature Range in $\mathrm{Ge}_{1-\mathrm{x}-\mathrm{y}} \mathrm{Ga}_{x} \mathrm{Sb}_{\mathrm{y}} \mathrm{Te}$ via Band Engineering and Hybrid Flash-SPS Processing, Inorganic Chemistry Frontiers, 2018, In press. DQI: 10.1039/C8QI00703A

(66) Rodríguez-Carvajal, J. Recent Advances in Magnetic Structure Determination by Neutron Powder Diffraction. Phys. B Condens. Matter 1993, 192 (1), 55-69.

(67) Kim, H.-S.; Gibbs, Z. M.; Tang, Y.; Wang, H.; Snyder, G. J. Characterization of Lorenz Number with Seebeck Coefficient Measurement. APL Mater. 2015, 3 (4), 041506.

(68) Clark, S. J.; Segall, M. D.; Pickard, C. J.; Hasnip, P. J.; Probert, M. I. J.; Refson, K.; Payne, M. C. First Principles Methods Using CASTEP. Z. Für Krist. - Cryst. Mater. 2009, 220 (5/6), 567-570.

(69) Perdew, J.P., Burke, K.; Ernzerhof, M. Generalized Gradient Approximation Made Simple. Phys. Rev. Lett. 1996, 77 (18), 3865-3868.

(70) Monkhorst, H. J.; Pack, J. D. Special Points for Brillouin-Zone Integrations. Phys. Rev. B 1976, 13 (12), 5188-5192.

(71) Blaha, P.; Schwarz, K.; Madsen, G.; Kvasnicka, D.; Luitz, J. WIEN2K: An Augmented Plane Wave plus Local Orbitals Program for Calculating Crystal Properties; Karlheinz Schwarz, Techn. Universität Wien, Austria: Wien, Austria, 2001.

(72) Tran, F.; Blaha, P.; Schwarz, K. Band Gap Calculations with Becke-Johnson Exchange Potential. J. Phys. Condens. Matter 2007, 19 (19), 196208.

(73) May, A. F.; Toberer, E. S.; Saramat, A.; Snyder, G. J. Characterization and Analysis of Thermoelectric Transport in N-Type Ba $\mathrm{Ga}_{16-x} \mathrm{Ge}_{30+x}$. Phys. Rev. B 2009, 80 (12), 125205.

(74) Toberer, E. S.; Zevalkink, A.; Crisosto, N.; Snyder, G. J. The Zintl Compound Ca5Al2Sb6 for LowCost Thermoelectric Power Generation. Adv. Funct. Mater. 2010, 20 (24), 4375-4380.

(75) Scheidemantel, T. J.; Ambrosch-Draxl, C.; Thonhauser, T.; Badding, J. V.; Sofo, J. O. Transport Coefficients from First-Principles Calculations. Phys. Rev. B 2003, 68 (12), 125210. 
(76) Madsen, G. K. H. Automated Search for New Thermoelectric Materials: The Case of LiZnSb. J. Am. Chem. Soc. 2006, 128 (37), 12140-12146.

(77) Madsen, G. K. H.; Singh, D. J. BoltzTraP. A Code for Calculating Band-Structure Dependent Quantities. Comput. Phys. Commun. 2006, 175 (1), 67-71.

(78) Li, C. C.; Drymiotis, F.; Liao, L. L.; Hung, H. T.; Ke, J. H.; Liu, C. K.; Kao, C. R.; Snyder, G. J. Interfacial Reactions between PbTe-Based Thermoelectric Materials and $\mathrm{Cu}$ and $\mathrm{Ag}$ Bonding Materials. J. Mater. Chem. C 2015, 3 (40), 10590-10596.

(79) Dow, H. S.; Oh, M. W.; Kim, B. S.; Park, S. D.; Min, B. K.; Lee, H. W.; Wee, D. M. Effect of Ag or Sb Addition on the Thermoelectric Properties of PbTe. J. Appl. Phys. 2010, 108 (11), 113709.

(80) He, J.; Kanatzidis, M. G.; Dravid, V. P. High Performance Bulk Thermoelectrics via a Panoscopic Approach. Mater. Today 2013, 16 (5), 166-176.

(81) Zhao, L.-D.; Dravid, V. P.; Kanatzidis, M. G. The Panoscopic Approach to High Performance Thermoelectrics. Energy Environ. Sci. 2013, 7 (1), 251-268.

(82) Qiu, B.; Bao, H.; Zhang, G.; Wu, Y.; Ruan, X. Molecular Dynamics Simulations of Lattice Thermal Conductivity and Spectral Phonon Mean Free Path of PbTe: Bulk and Nanostructures. Comput. Mater. Sci. 2012, 53 (1), 278-285.

(83) Zhang, L.; Wang, J.; Cheng, Z.; Sun, Q.; Li, Z.; Dou, S. Lead-Free SnTe-Based Thermoelectrics: Enhancement of Thermoelectric Performance by Doping with Gd/Ag. J. Mater. Chem. A 2016, 4 (20), 7936-7942.

(84) Jood, P.; Ohta, M.; Kunii, M.; Hu, X.; Nishiate, H., Yamamoto, A.; Kanatzidis, M. G. Enhanced

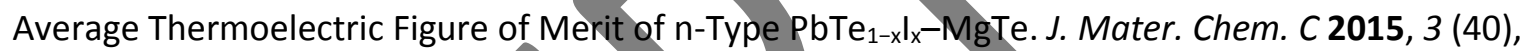
10401-10408.

(85) Li, Z.-Y.; Li, J.-F. Fine-Grained and Nanostructured $\mathrm{AgPb}_{m} \mathrm{SbTe}_{m+2}$ Alloys with High Thermoelectric Figure of Merit at Medium Temperature. Adv. Energy Mater. 2014, 4 (2), 300937.

(86) Ning, H.; Mastrorillo, G. D.; Grasso, S., Du, B.; Mori, T.; Hu, C.; Xu, Y.; Simpson, K.; Maizza, G.; Reece, M. J. Enhanced Thermoelectric Performance of Porous Magnesium Tin Silicide Prepared Using Pressure-Less Spark Plasma Sintering. J. Mater. Chem. A 2015, 3 (33), 17426-17432.

(87) Girard, S. N.; Schmidt-Rohr, K.; Chasapis, T. C.; Hatzikraniotis, E.; Njegic, B.; Levin, E. M.; Rawal, A.; Paraskevopoulos, K. M.; Kanatzidis, M. G. Analysis of Phase Separation in High Performance PbTe-PbS Thermoelectric Materials. Adv. Funct. Mater. 2013, 23 (6), 747-757.

(88) Wang, H.; LaLonde, A. D.; Pei, Y.; Snyder, G. J. The Criteria for Beneficial Disorder in Thermoelectric Solid Solutions. Adv. Funct. Mater. 2013, 23 (12), 1586-1596.

(89) Al Rahal Al Orabi, R.; Mecholsky, N. A.; Hwang, J.; Kim, W.; Rhyee, J.-S.; Wee, D.; Fornari, M. Band Degeneracy, Low Thermal Conductivity, and High Thermoelectric Figure of Merit in SnTe-CaTe Alloys. Chem. Mater. 2016, 28 (1), 376-384.

(90) Tan, G.; Shi, F.; Doak, J. W.; Sun, H.; Zhao, L.-D.; Wang, P.; Uher, C.; Wolverton, C.; Dravid, V. P.; Kanatzidis, M. G. Extraordinary Role of Hg in Enhancing the Thermoelectric Performance of PType SnTe. Energy Environ. Sci. 2014, 8 (1), 267-277.

(91) Tan, G.; Zhao, L.-D.; Shi, F.; Doak, J. W.; Lo, S.-H.; Sun, H.; Wolverton, C.; Dravid, V. P.; Uher, C.; Kanatzidis, M. G. High Thermoelectric Performance of $p$-Type SnTe via a Synergistic Band Engineering and Nanostructuring Approach. J. Am. Chem. Soc. 2014, 136 (19), 7006-7017.

(92) Goldsmid, H. J.; Sharp, J. W. Estimation of the Thermal Band Gap of a Semiconductor from Seebeck Measurements. J. Electron. Mater. 1999, 28 (7), 869-872.

(93) Wang, J. L.; Wang, H.; Snyder, G. J.; Zhang, X.; Ni, Z. H.; Chen, Y. F. Characteristics of Lattice Thermal Conductivity and Carrier Mobility of Undoped PbSe-PbS Solid Solutions. J. Phys. Appl. Phys. 2013, 46 (40), 405301. 


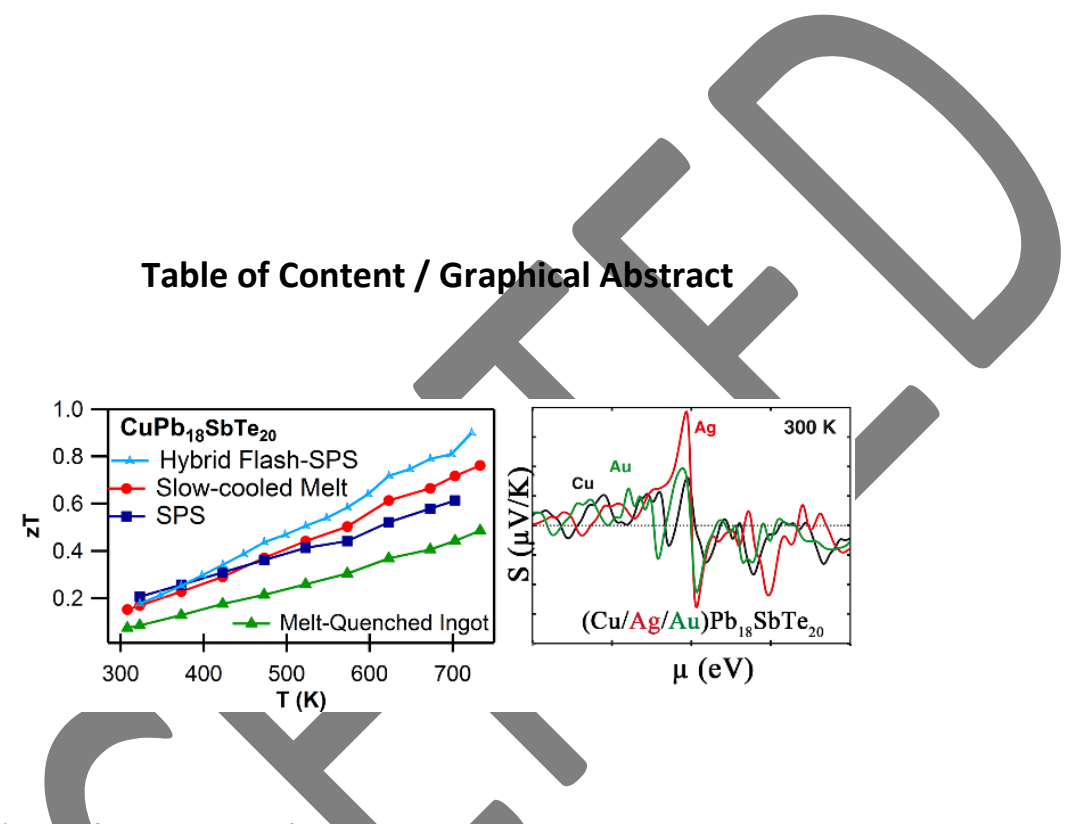

The recently developed 'out of equilibrium' Hybrid Flash-SPS technique, with extremely high heating rate $\left(10,000{ }^{\circ} \mathrm{C} / \mathrm{min}\right)$ and short processing time (3 seconds), provides a way to achieve a better trade-off between electrical and thermal transport properties by decreasing the carrier concentration and lattice thermal conductivity without degrading the carrier mobility, manifests an enhanced thermoelectric figure of merit, $z T \sim 0.9$ at $723 \mathrm{~K}$ in $\mathrm{CuPb}_{18} \mathrm{SbTe}_{20}$ and outperforms other classical processing techniques. 